\title{
The rationale and relevance of existing cadres of frontline health workers and potential for new mid-level cadres
}

Oladimeji Oladepo

Ekechi Okereke

Population Council

Akinwumi Akinola

Population Council

Follow this and additional works at: https://knowledgecommons.popcouncil.org/departments_sbsr-rh

Part of the Community-Based Learning Commons, Demography, Population, and Ecology Commons, Family, Life Course, and Society Commons, and the International Public Health Commons

How does access to this work benefit you? Let us know!

\section{Recommended Citation}

Oladepo, Oladimeji, Ekechi Okereke, and Akinwumi Akinola. 2018. "The rationale and relevance of existing cadres of frontline health workers and potential for new mid-level cadres," Human Resources for Health Project. Abuja: Population Council. 


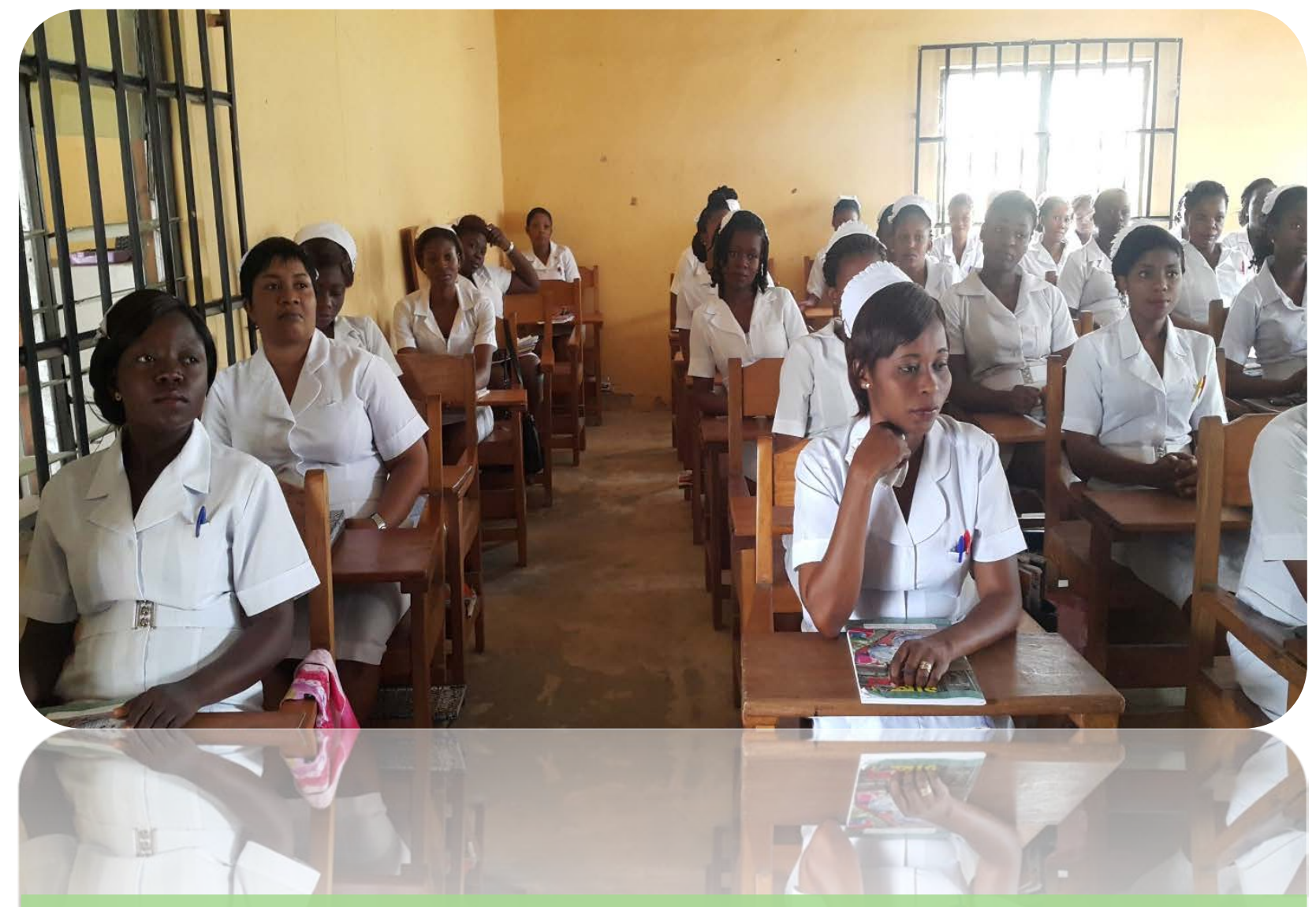

THE RATIONALE AND RELEVANCE OF EXISTING CADRES OF FRONTLINE HEALTH WORKERS AND POTENTIAL FOR NEW MID-LEVEL CADRES 
Ideas. Evidence. Impact.

The Population Council confronts critical health and development issues-from stopping the spread of HIV to improving reproductive health and ensuring that young people lead full and productive lives. Through biomedical, social science, and public health research in 50 countries, we work with our partners to deliver solutions that lead to more effective policies, programs, and technologies that improve lives around the world. Established in 1952 and headquartered in New York, the Council is a nongovernmental, non-profit organization governed by an international board of trustees.

Population Council

Nigeria Country Office

No. 16, House 4, P.O.W. Mafemi Crescent

Utako, FCT Abuja

Nigeria.

Tel: +23492914878

popcouncil.org

\section{ABOUT THE HUMAN RESOURCES FOR HEALTH (HRH) PROJECT}

This document was developed by Population Council through the Human Resources for Health $(\mathrm{HRH})$ project, "Enhancing the Ability of Frontline Health Workers to Improve Health in Nigeria", funded by Global Affairs Canada (GAC). The five-year health systems strengthening project is implemented in Nigeria by the World Health Organization (WHO), Population Council and Global Health Workforce Alliance (GHWA). The project has two focal states, Cross River and Bauchi, but also works at the federal level through the Federal Ministry of Health and regulatory bodies, specifically the Nursing and Midwifery Council of Nigeria (NMCN) and the Community Health Practitioners' Registration Board of Nigeria (CHPRBN), as well as pre-service training institutions.

The project aims to improve the quality and quantity of FLHWs in Bauchi and Cross River states, build capacity for HRH management at federal and state levels and contribute to reducing the burden of disease among women, newborn and children.

Suggested Citation - Oladepo O., Okereke E., Akinola A., 2018. "The Rationale and Relevance of existing cadres of frontline health workers and potential for new mid-level cadres." Human Resources for Health Project: Population Council.

(C)2018 The Population Council, Inc.

The views and opinions expressed within this report do not necessarily reflect the views of the donor for the Enhancing the Ability of Frontline Health Workers to Improve Health in Nigeria Project, which is Global Affairs Canada (GAC). 


\section{Table of Contents}

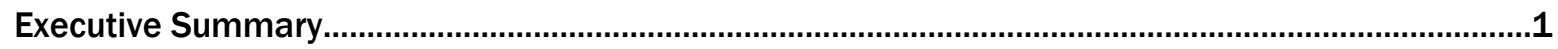

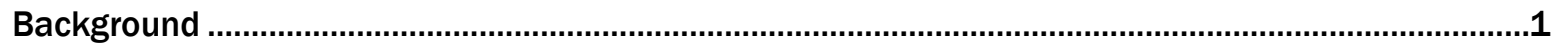

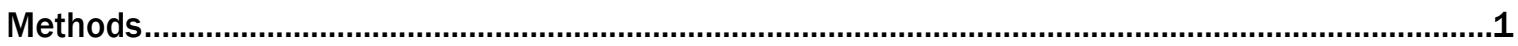

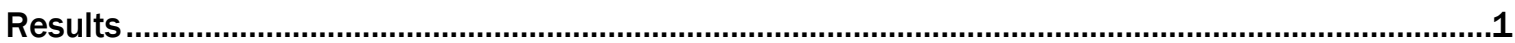

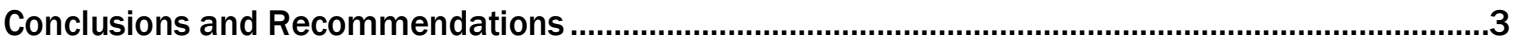

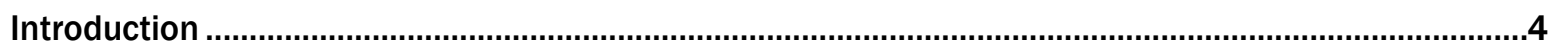

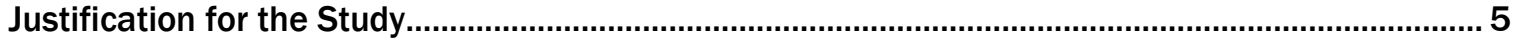

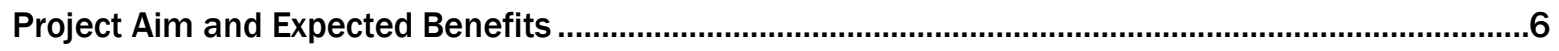

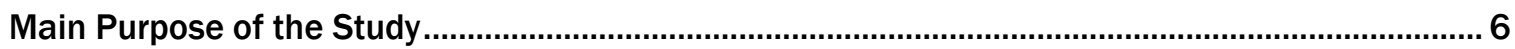

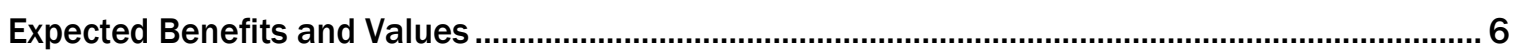

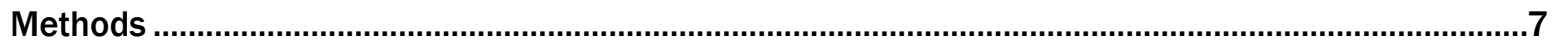

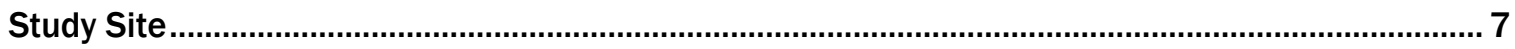

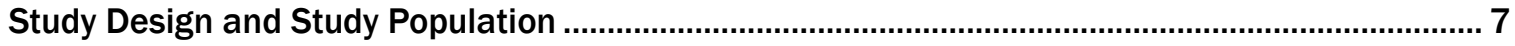

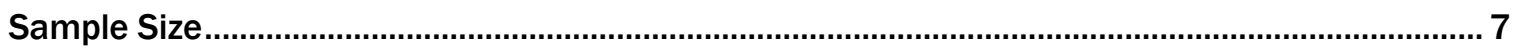

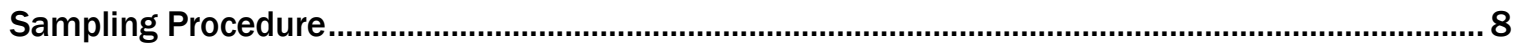

Development of Key Instruments: Key Informant Guide and Survey Questionnaires.................... 9

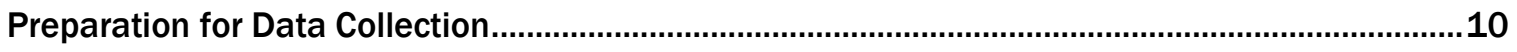

Field Work

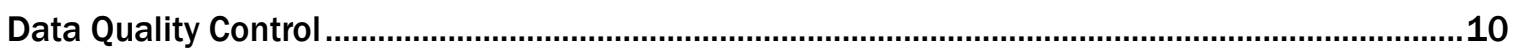

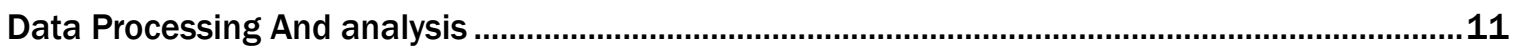

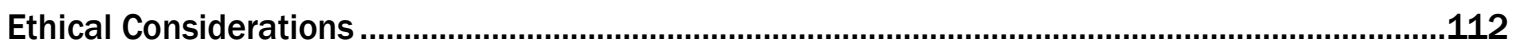

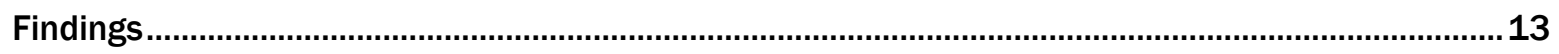

Maternal, Newborn and Child Disease Burden in Communities Served by FLHWs ........................13

FLHWs' Knowledge of Prescribed PHC Roles and Critical MNCH Content .....................................15

FLHWs' Performance in Critical, Life-Saving Maternal and Newborn Interventions .......................15

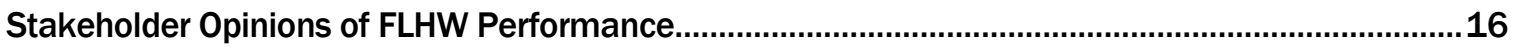

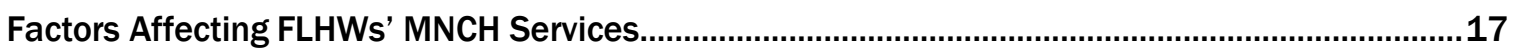

Stakeholder Opinions of FLHWs' PHC MNCH Roles and Performance............................................19

Stakeholder Suggestions for Expanding FLHWs' Rural PHC MNCH Services................................20

Stakeholder Opinions of a New FLHW Cadre for Rural PHC MNCH Services ...............................21

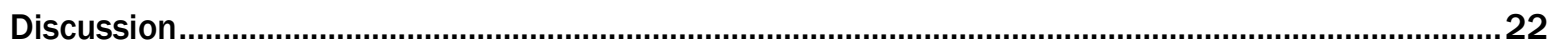

FLHW Demographics, Knowledge of Roles, and MNCH Content.................................................22

FLHW Performance in Critical, Life-Saving Maternal and Newborn Interventions.........................22

Personal, Organizational, and Community Factors Affecting FLHWs' MNCH Services...................223

Is There Potential for a New Cadre of PHC Workers in Nigeria?....................................................24

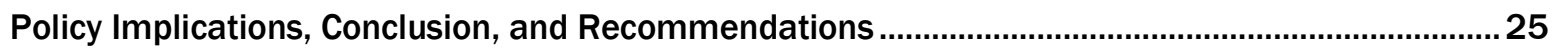

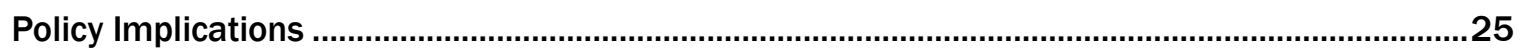

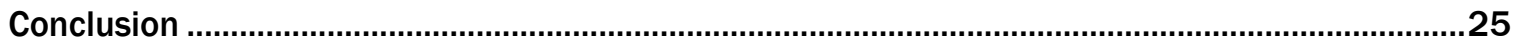

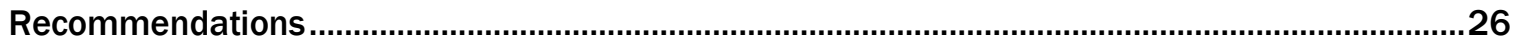

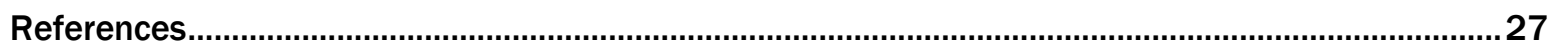

Appendices ............................................................................................ Error! Bookmark not defined. 


\section{List of Tables}

Table 1: Study Instruments, Participants and Issues Addressed in Each Instrument....................... 9

Table 2: Number of health facilities, FLHWs, Clients and Households interviewed in study LGAs 10

Table 3: Reported IIInesses of Women in the last 12 months..........................................................29

Table 4a: Reported IIInesses of Newborn in the last 12 months .......................................................30

Table 5a: Reported Causes of Death for Women and Under-Five Children in the Six Months Prior to Data Collection ..................................................................................................... 32

Table 6: FLHW Socio-Demographic Information, by Cadre and State ...............................................34

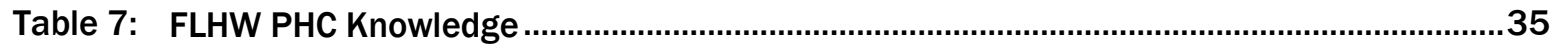

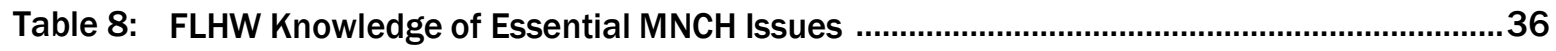

Table 9: Average Number of Clients Seen in One Day, by FLHW Cadre..............................................37

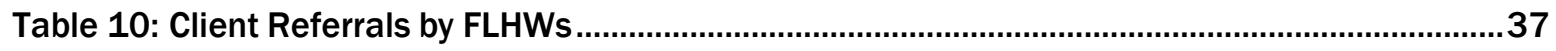

Table 11: Client Referrals by FLHWs (Disaggregated by State) ........................................................38

Table 12: Households Visited in the Past Six Months by FLHWs............................................................ 39

Table 13: Support for Different FLHW Cadres from Village and Ward Development Committees ... 39

Table 14: Staff Experiences with Stock Outs (Equipment and Supply), Bauchi ................................... 40

Table 15: Staff Experiences with Stock Outs (Equipment and Supply), Cross River ......................... 41

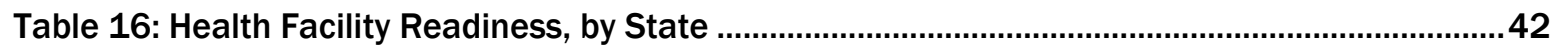

Table 17: Major Welfare Challenges Facing FLHWs....................................................................... 42 


\section{Acknowledgments}

Population Council Nigeria would like to acknowledge, and express thanks for, the generous funding for the Human Resources for Health project by Global Affairs Canada (GAC), as well as the support and partnership from the World Health Organization (WHO) in Nigeria. Special thanks go to government officials from Bauchi and Cross River states for their support and enabling environments that made this research study possible.

Appreciation and heartfelt thanks are also extended to all research supervisors, assistants, and data collectors for their tireless efforts before, during, and after the data collection process of this research study as well as the Consultant hired to support the design and execution of this research, Professor Oladimeji Oladepo of the University of Ibadan, Nigeria.

Sincere appreciation is also expressed to Dr. Sylvia Adebajo, the Country Director for Population Council Nigeria as well as the entire HRH team at Population Council Nigeria (Ekechi Okereke [HRH Project Director], Friday Joseph [HRH Project Manager], Godwin Unumeri [Cross River State HRH Programme Coordinator], Ibrahim Suleiman [Bauchi State HRH Programme Coordinator] and Aisha Jibril [HRH Program Officer]) for ensuring the completion of this piece of research. The contributions of George Eluwa, Osasuyi Dirisu and Akinwumi Akinola of Population Council Nigeria's Research team towards the completion of this report are also acknowledged. In addition, we acknowledge the constructive feedback received from Michelle Hindin, Program Director for Reproductive Health at Population Council, during the finalization of this report.

Finally, we appreciate the community leaders and community members within selected communities in Bauchi and Cross River states who provided support and useful information during the field work for the study. 


\section{List of Acronyms}

ACT

AIDS

AMTSL

ANC

ART

ARV

BCG

CHEW

CHOS

CHW

CHPRBN

CMAM

CSM

DDC

DTP

FLHW

FMoH

FP

GAC

HIB

HIV

$\mathrm{HRH}$

HR

IMR

IPTP

IUD

IYCF

JCHEW

KMC

LGA

LLITN

MDG

MMR

$\mathrm{MNCH}$

MoU

MSS

NDHS

NPC

NPHCDA

OPV

ORS

ORT

PCV
Artemisinin Combination Therapy

Acquired Immune Deficiency Syndrome

Acute Management of Third Stage Labor

Antenatal Care

Anti-Retroviral Therapy

Anti-Retroviral

Bacillus Calmette-Guerin

Community Health Extension Worker

Community Health Officer

Community Health Worker

Community Health Practitioners Registration Board of Nigeria

Community-based Management of Acute Malnutrition

Cerebro-Spinal Meningitis

District Development Committee

Diphtheria, Tetanus, Pertussis

Frontline Health Worker

Federal Ministry of Health

Family Planning

Global Affairs Canada

Haemophilus Influenza Type B

Human Immuno-Deficiency Virus

Human Resources for Health

Human Resources

Infant Mortality Rate

Intermittent Preventive Treatment in Pregnancy

Intra-Uterine Device

Infant and Young Child Feeding

Junior Community Health Extension Worker

Kangaroo Mother Care

Local Government Area

Long Lasting Insecticide Treated Net

Millennium Development Goal

Maternal Mortality Rate

Maternal, Newborn and Child Health

Memorandum of Understanding

Midwives Services Scheme

National Demographic Health Survey

National Population Commission

National Primary Healthcare Development Agency

Oral Polio Vaccine

Oral Rehydration Salt

Oral Rehydration Therapy

Pneumococcal Conjugate Vaccine 


$\begin{array}{ll}\text { PHC } & \text { Primary Health Care } \\ \text { PMtCT } & \text { Prevention of Mother-to-Child Transmission } \\ \text { PMV } & \text { Patent Medicine Vendor } \\ \text { PPH } & \text { Postpartum Hemorrhage } \\ \text { RDTK } & \text { Rapid Diagnostic Testing Kit } \\ \text { SAM } & \text { Severe Acute Malnutrition } \\ \text { SAPI } & \text { Smartphone-assisted Personal Interview } \\ \text { SBA } & \text { Skilled Birth Attendant } \\ \text { SMoH } & \text { State Ministry of Health } \\ \text { SPSS } & \text { Statistical Package for Social Sciences } \\ \text { TBA } & \text { Traditional Birth Attendant } \\ \text { UNICEF } & \text { United Nations International Children's Emergency Fund } \\ \text { UN } & \text { United Nations } \\ \text { VDC } & \text { Village Development Committee } \\ \text { WHO } & \text { World Health Organization }\end{array}$




\section{Executive Summary}

\section{BACKGROUND}

Frontline Health Workers (FLHWs) are critical for preventive and curative health care services for mothers, newborns, and children in primary health care settings. The operational definition of a FLHW, for this study (and the Human Resources for Health project overall), is a nurse, midwife, Community Health Officer (CHO), Community Health Extension Worker (CHEW), or Junior Community Health Extension Worker (JCHEW) authorized to practice after a prescribed examination by an institution recognized by a state or national board. FLHWs tend to have more immediate access to clients and patients presenting for primary health care $(\mathrm{PHC})$ than other cadres of health care workers including doctors, providing initial care to persons in need of health services.

FLHWs are expected to perform necessary maternal, newborn, and child ( $\mathrm{MNCH}$ ) services appropriately and effectively; however, few studies have investigated the extent to which FLHWs perform requisite PHC services, resulting in limited evidence in the literature on not only FLHWs' performance of PHC but the inhibiting factors of their performance as well. This study seeks to better understand not only FLHWs' knowledge and performance of $\mathrm{MNCH}$ services, but the factors promoting and inhibiting their services in selected rural local government areas (LGAs) of Nigeria's Bauchi and Cross River states. It also investigates the potential for a new PHC health care worker cadre, soliciting stakeholders' perceptions about its feasibility for addressing maternal and newborn disease burdens in rural communities.

\section{METHODS}

The study utilized quantitative and qualitative data collection in both Bauchi and Cross River, with a descriptive cross-sectional design for the quantitative component. One hundred fourteen (114) FLHWs, 66 PHC facility heads, 256 female $\mathrm{MNCH}$ service users, 1,548 heads of households, and 44 stakeholders were selected through multi-stage and purposive sampling techniques. FLHWs' knowledge of their prescribed roles was assessed, with critical $\mathrm{MNCH}$ content measured on a 13-point scale. Their performance of $\mathrm{MNCH}$ activities for the six months preceding the study was assessed, along with health sector stakeholders' perceptions of their performance.

Descriptive statistics summarize the survey data, and results are presented using frequencies, percentages, and means, as appropriate. Qualitative data were organized and coded, with Atlas Ti. software content analysis identifying emerging themes and sub-themes. Narratives were constructed from stakeholder interviews for better understanding of their opinions and perceptions.

Ethical approval was obtained from the two project states' research ethical review committees in addition to ethical approval from the Population Council's Institutional Review Board (IRB) in the United States (US).

\section{RESULTS}

A high number of women's and children's deaths were reported by household heads in this study in selected communities served by FLHWs. Over a six month period, 64 deaths among ${ }^{12544}$ women (Bauchi 51.1\%, Cross River 48.9\%), 79 deaths among 657 newborns (Bauchi $67.1 \%$, Cross River $32.9 \%$ ), and 111 deaths among 2,446 children under the age of five years (Bauchi 81.1\%; Cross River, 18.9\%) were reported.

1 There were 2,544 women within 1,548 households, as some households have more than one resident woman 
Shortages of FLHWs (nurses, midwives and community health workers) were evident: a total of 114 were available in all $66 \mathrm{PHC}$ facilities included for the study. Under half (46.5\%) of FLHWs were CHEWs, although the proportion varied by state (Bauchi $43.4 \%$, Cross River 56.6\%). The second largest FLHW category was JCHEWs (44.7\%--Bauchi 46.8\%, Cross River 53.2\%), followed by CHOs, at 6.1 percent total (Bauchi $2 \%$, Cross River 9.2\%). The number of nurses and midwives at the rural PHC facilities in the study was extremely low (nurses $0.9 \%$, midwives 1.8\%). Bauchi state employs more male FLHWs (65.3\%), with more female FLHWs (76.9\%) in Cross River.

More CHEWs, compared to JCHEWs, were knowledgeable of their expected PHC roles. More than two thirds (70\%) of all FLHWs were aware of critical MNCH content including antenatal care (ANC), counseling, danger signs and complications in pregnancy, management of delivery, and child health problems.

FLHWs' self-reported performance for the preceding six months show that CHEWs provided more MNCH services, with average daily client estimates of 21 in Bauchi and seven in Cross River, than JCHEWs (Bauchi $n=16$, Cross River $n=5$ ). Overall, about 50 percent of CHEWs conducted infant deliveries in both states, followed by JCHEWs (Bauchi 30.6\%, Cross River 25.9\%), due especially to the scarcity of nurses and midwives in PHC facilities. More JCHEWs (97.7\%) referred clients and completed referral forms (87.2\%) than CHEWs (referrals by $90.2 \%, 81.1 \%$ completed referral forms). Many FLHWs in PHCs and health clinics referred clients (PHC 86.9\%, clinic 83.3\%) for higher level care and completed referral forms. Over 80 percent of FLHWs expressed willingness to perform a majority of the responsibilities in the national task shifting and -sharing policy.

Over 70 percent of FLHWs cited personal attributes (motivation to serve, contentment with serving the community, job satisfaction) in addition to previous $\mathrm{MNCH}$ training in the last five years and community support from village or ward development committees as factors in their job performance. Their primary performance barriers are inadequate knowledge of critical $\mathrm{MNCH}$ content and non-availability of equipment and materials when needed: More than one third of CHEWs did not have sufficient access to a fetoscope (Bauchi 50\%, Cross River 46.7\%), weighing scale (Bauchi 40.9\%, Cross River 56.7\%), table for gynecological examination (Bauchi 31.8\%, Cross River 36.7\%), or delivery couch (Bauchi $22.7 \%$, Cross River 46.7\%). A similar trend was observed for JCHEWs. Inadequate amenities were also reported by CHEWs, for water supply (Bauchi 36.4\%, Cross River 33.3\%), generators (Bauchi 40.9\%, Cross River 30\%), along with infrastructural defects such as leaking roofs, broken doors and windows common at study facilities. Salary delays and benefit complications were reported. These barriers identified in the quantitative survey reinforce those identified by the stakeholders during qualitative data collection.

To address these human resources for health $(\mathrm{HRH})$ challenges, most study participants in Bauchi suggested employing unemployed health care workers, while study participants in Cross River proposed training or re-training and assimilating traditional birth attendants (TBAs) in the state's health sector. A common suggestion in both states was reinforcing FLHWs' pre-service training institutions for adequate FLHW supply and quality. The head of one health training institution stated:

"The only available opportunity now is to scale up the establishment of health training institutions for frontline health workers' like the schools, colleges of nursing...such that these can become accredited and start producing as many frontline health workers as possible and then we would have adequate number of nurses and midwives..."

The opinions of stakeholders were divided on whether to create a new cadre of FLHWs for rural MNCH services. In Bauchi a majority support the idea, evinced by a government official:

"If at all there is opportunity to do so, yes, it is necessary to create a new cadre as this will make us to have additional staff...it will be better"

Most participants in Cross River, however, oppose the idea, represented by one school head's remarks:

"Well, presently, I don't think we need that...there is really no need to create a new cadre for health workers...rather we should look at improving the skills and the efficiency of the ones we already have..." 


\section{CONCLUSIONS AND RECOMMENDATIONS}

This study's findings show a shortage of all FLHW cadres-and for nurses and midwives, this shortage is critical-as well as an insufficient equipment and materials required for FLHWs' quality MNCH services. This situation, coupled with FLHWs' inadequate knowledge of critical $\mathrm{MNCH}$ issues and poor staff welfare, reveal that much still needs to be done to strengthen $\mathrm{HRH}$ in rural communities in Nigeria.

Urgent action is needed for:

- Increasing the numbers of FLHWs and improving their skills for $\mathrm{MNCH}$ services in rural communities, especially for nurses and midwives;

- Expanding the number of health training institutions to escalate FLHW training for meeting minimum staffing levels in PHC facilities;

- Implementing in-service $\mathrm{MNCH}$ competency-based training for FLHWs, to improve their knowledge of critical MNCH content and improve the quality of their service delivery;

- Creating enabling working conditions guaranteeing FLHWs' access to adequate and sustainable quantities of required supplies, with guaranteed benefit packages of remunerations and incentives, with federal and state governments improving FLHW motivation and retention by providing adequate infrastructure, equipment, and drugs at rural health facilities along with sufficient monetary compensation;

- Introducing and properly implementing structured performance-based incentives for rural health care workers;

- Enforcing government policies and guidelines on the minimum levels of required equipment in PHC facilities; and

- Increasing investments by ward and village development committees and empowering their use of innovative approaches to engage community volunteers' in complementary efforts for FLHW PHC services, and within rural communities. 


\section{Introduction}

Nigeria's primary health care (PHC) system is a key source of preventive and curative services for mothers and their children including newborns. Nigeria's PHC system offers critical, life-saving maternal, newborn and child health (MNCH) interventions such as antenatal care (ANC)-for preventing, detecting, and treating health conditions during pregnancy-with basic and comprehensive emergency obstetric and newborn care, for both normal delivery or delivery with moderate complications, or referrals of those with serious complications for more specialized emergencies, followed by postnatal care (PNC) for mothers and their newborns, not only for preventing, detecting, and treating postnatal problems but promoting hygienic child care and early and exclusive breastfeeding.

Previous studies have shown high death rates among women due to pregnancy and childbirth-maternal mortality. Nigeria's Demographic and Health Surveys (NDHS) in 2003, 2008, and 2013 report maternal mortality ratios (MMR), respectively, of 800,545 , and 576 deaths per 100,000 live births. The proportions of these deaths differ greatly across many parts of the country, but are higher in northern Nigeria. These high proportions of deaths have been linked to lack of skilled birth attendants (SBAs) and a preference for home births, mostly conducted by unskilled birth attendants-by woment themselves, family members, or traditional birth attendants (TBAs) (FMoH 2014).

Similarly, studies have shown high death rates among newborns and children under the ages of five years. In 2013 NDHS estimated neonatal and under-five mortality rates of 37 and 128 per 1,000 live births, with higher rates in rural areas. Another study indicated approximately 261,549 annual deaths among neonates, and 800,000 among children younger than five, which together constitute 11 percent of the total global deaths of under-five children (UNICEF, WHO, World Bank 2014). Regrettably, as much as 40 percent of childhood deaths in Nigeria are due to common, preventable diseases (Muhammed Lecky et al. 2012) such as malaria and diarrhea, worsened by malnutrition and its attendant risks.

Efficient $\mathrm{MNCH}$ services, to reduce the burden of maternal and child mortality at the PHC level, requires availability of dynamic and skilled frontline health workers (FLHWs)-nurses and midwives, Community Health Officers (CHOs), and Community Health Extension Workers (CHEWs)-but it has been reported that a major barrier in Nigeria to accessing essential health care services is a shortage and inequitable distribution of appropriate health workforce cadres ( $F M o H ~ 2014)$. The same report indicates a shortage of virtually all cadres of health care workers, resulting in poor utilization of thousands of health facilities in the country, for essential services for ANC, delivery, PNC, infant welfare, HIV, malaria, tuberculosis, and other basic services. FLHW pre-service education, for addressing these shortages, seems to indicate inadequate supply for a desired health workforce to deliver quality services. The National Primary Health Care Development Agency (NPHCDA) reported, as of 2009, a total of $483 \mathrm{CHOs,} 3,084 \mathrm{CHEWs}$, and 3,421 JCHEWs graduated from training institutions.

There are inadequate numbers of FLHWs for PHC services. In 2009, 36,737 community health workers (CHWs) and 5,604 skilled personnel (doctors, nurses, midwives) were working in PHC facilities (NPHCDA 2009), with 28 percent of CHWs health assistants, 27 percent CHEWs, 11 percent JCHEWs, and four precent $\mathrm{CHOs}$, with less than eight percent nurses or nurse/midwives. Another study by Midwives Services Scheme Series (MSS Series) in 2012 indicated that, as of December 2011, 3,372 midwives and 918 CHEWs were employed across the country, but with estimated requirements of 4,000 midwives and 1,000 CHEWs, resulting in shortfalls of 16 percent for midwives and 10 percent for CHEWs (MSS Series 2012). Compounding these shortages of staff is the uneven distribution of FLHWs, with a larger proportion in urban areas than rural areas, where most deaths of women and children occur.

FLHWs' pre-service training curricula, from 2006, and still in use in 2016, lacked relevant RH and health management such as current methods of care for mothers and children during pregnancy, childbirth, and post childbirth, delivery of long term, reversible contraceptives, advanced community health care, 
emerging and re-emerging diseases, essential medicines, and modern data management (Oladepo 2014). These content gaps could affect FLHWs' adequate MNCH knowledge. NPHCDA and FMoH just approved revised national $\mathrm{CHW}$ training curricula featuring current $\mathrm{MNCH}$ knowledge and skills, and the GAC-funded $\mathrm{HRH}$ project supported the revision of Bauchi's College of Nursing and Midwifery curriculum and procedural manual, in addition to similar documents for Cross River's nursing and midwifery schools.

To address the rural health worker shortage and improve MNCH indices, in 2009 Nigeria's government instituted a national Midwifery Service Scheme (MSS), through which newly graduated, unemployed, or retired midwives were deployed to rural PHC facilities for one year, to provide essential delivery care (Abimbola 2012). An assessment of the program showed uneven improvement in women's and children's death rates in Nigeria's six geopolitical zones, and despite midwives' presence, many women still deliver at home in many parts of the country (ibid). Abimbola further discusses major problems in the program including inability to recruit, train, and re-tain adequate numbers of midwives, and poor commitment by both state and local governments for paying salaries and maintaining infrastructures. The findings of another study in three northern states show that most MSS midwives were dissatisfied with their job, especially with lack of opportunities for career growth and poor promotion opportunities, accommodation safety, and inadequate salaries and poor welfare packages. These challenges meant that 38 percent planned to leave the program within two years-and 18 percent within one year (Adegoke et al. 2015).

In addition to MSS, the government developed a task shifting and -sharing policy in 2009 to rationally redistribute health workforce tasks where appropriate (FMoH 2014). This policy is expected to be implemented by governments at all levels, to attain fundamental human resources for health $(\mathrm{HRH})$, both in quantity and skills mix, and address the mal-distribution of health workers at all facilities, reinforced by quality health workforce training (FMoH 2014).

The extent to which FLHWs are willing to perform the tasks assigned in the new policy has not been explored. Meanwhile, inadequate resources for FLHWs' effective services have been reported at PHC facilities, for equipment, medicines, and supplies (Nnebue et al. 2014, Musa and Ejembi 2004, Adeniyi et al. 2001), and it is important to assess how lack of these resources interferes with FLHW performance.

\section{JUSTIFICATION FOR THE STUDY}

Although FLHWs provide $\mathrm{MNCH}$ services within communities, especially rural areas, to mothers and children, little is known about their functions and levels of performance. Recently, there have been concerns about FLHW performance after dismal statistics including high rates of maternal morbidity and mortality, and poor outcomes for children and newborns, especially in rural areas. There is broad consensus within Nigeria's health policy circles that FLHWs are an appropriate area of focus for improving $\mathrm{MNCH}$ service access; hence renewed calls to better understand the continued relevance of PHC FLHWs, in the face of high numbers of illnesses and deaths of women and children. It is also being debated whether a new cadre of FLHWs should be created for PHC, to expand FLHW delivery of rural PHC MNCH services.

There are presently few concrete answers to important questions on FLHWs working in rural areas: What are the $\mathrm{MNCH}$ burdens of women and children in communities served by FLHWs? How knowledgeable are FLHWs about their prescribed PHC roles? Of critical MNCH content? How does their knowledge, or lack thereof, affect their job performance and $\mathrm{MNCH}$ service delivery? What $\mathrm{MNCH}$ services do FLHWs perform at rural PHC facilities? How satisfied are FLHWs' MNCH clients? What factors-personal, organizational, community-influence FLHWs' MNCH services? What are the evaluations of rural women's and children's health statuses by Nigeria's health sector stakeholders? What problems do FLHWs face? Is there a place for a new health worker cadre within the present PHC personnel structure?

It is hoped that this study will inform health care policy and PHC practice, especially for FLHWs working in rural local government areas (LGAs), so these health care personnel can better deliver critical, life-saving $\mathrm{MNCH}$ interventions to populations in need of health care. 


\section{Project Aim and Expected Benefits}

\section{PRIMARY PURPOSE}

The purpose of this study is to better understand the rationale and relevance of existing FLHW cadres for providing $\mathrm{MNCH}$ services at the PHC level in Nigeria, and the potential for a new mid-level FLHW cadre within the PHC personnel structure and framework. Ultimately, this research will provide information for better understanding HRH in Nigeria for MNCH services in rural LGAs in Bauchi and Cross River states.

The specific objectives of this study are to:

- Assess the extent to which FLHWs are able to meet the MNCH needs of their communities

- Assess FLHWs' knowledge of their roles in $\mathrm{MNCH}$ service provision at the PHC level

- Assess FLHWs' knowledge of critical MNCH content and its effect on their performance

- Assess existing FLHWs' provision of MNCH services

- Identify factors affecting FLHW performance and contextual factors, i.e. personal, organizational, and community

- Explore stakeholders' opinions of FLHWs' PHC MNCH role and assessments of their performance

- Explore stakeholders' opinions of whether there is potential and need for a new mid-level cadre in the current PHC personnel structure.

The study was guided by the work of Elliot et al. (in Bloom et al. 2009), focusing on FLHWs' performance of core $\mathrm{MNCH}$ functions, and their relationships and exchanges with users of services (mothers and their children), as well as the factors influencing FLHWs' performance in PHC facilities.

\section{EXPECTED BENEFITS AND VALUES}

The findings from this study should provide insights into FLHWs' prospects, and their constraints, for delivering critical, life-saving $\mathrm{MNCH}$ interventions in Bauchi and Cross River states, thereby enriching policy dialogue in Nigeria on better HRH policies and strategies. These study tools and investigative methods can be used by other states in the future. 


\section{Methods}

\section{STUDY SITE}

The study was conducted in Bauchi (North-East) and Cross River (South-South) states in Nigeria. Both states were selected for the study due to their status as HRH project focal states, in addition to the possibility of contrasting outcomes for two geographically and linguistically different areas. In both states, $\mathrm{MNCH}$ indices are poor.

\section{STUDY DESIGN} AND STUDY POPULATION

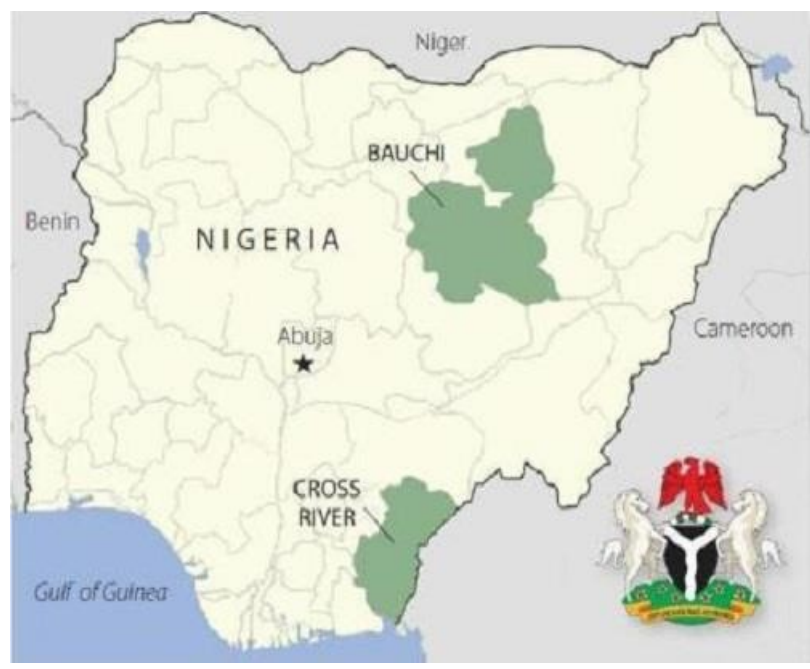

The study was descriptive and cross-sectional, employing a two-stage stratified sampling design with quantitative and qualitative data collection methods. The outcomes of interest are measures of knowledge, performance, and factors affecting FLHWs' performance, as well as Nigerian health sector stakeholders' perceptions. The key study populations are:

- FLHWs-Nurses, Midwives, and Community Health Workers (CHWs) including Community Health Officers (CHOs), Community Health Extension Workers (CHEWs) and Junior Health Extension Workers (JCHEWs) working at health posts, PHC clinics, PHC centers, and comprehensive health care centers

- Women utilizing MNCH services at PHC facilities

- Diverse primary stakeholders (health policymakers, managers, and service providers, at state and community levels), and

- Heads of households in selected communities.

\section{SAMPLE SIZE}

Different sample sizes were used for the quantitative survey and qualitative interviews:

Quantiative:

- FLHWs survey: All 114 FLHWs-CHEWs, JCHEWs, CHOs, nurses, midwives-in selected facilities were enrolled, utilizing the inclusion criteria female or male health worker...working in the selected PHC facility...12 months prior to the study, providing $\mathrm{MNCH}$ services in the selected PHC facility and consenting to participate. Exclusion criteria constiuted FLHWs on leave or who have travelled out of the LGAs, or unavailable during the study period, or did not consent to participate.

- Facility mapping and inventory survey: 66 PHC facilities (health posts, clinics, centers) representing 50 percent of all available PHC facilities within the two randomly selected rural study LGAs in each state were selected, based upon the sampling approach in an earlier study (Adeniyi et al. 2004).

- Client exit survey: A purposive sample of 256 exiting clients, comprised of women who had just obtained $\mathrm{MNCH}$ services from FLHWs-either for themselves, their newborn, or under-five childduring the data collection period, based upon a previous study (Oladepo et al. 2014). 
- Household survey: The sample size for heads of households was calculated with the following assumptions: a sided test with a precision of five percent and 30 percent prevalence $(P)$ of maternal, newborn and child deaths due to pregnancy, abortion, or childbirth within the population (based on consultation with officials of the state ministries of Health and epidemiologists from the University of Ibadan) and a 95 percent confidence level. The minimum sample size was estimated to be 323 household heads per LGA and thus 646 household heads per state ( 2 study LGAs per state) and 1,292 for both states, which was increased to 1,548 to accommodate incomplete responses and attrition during data collection.

Qualitative:

- Key informant interviews: A purposive sample of 44 stakeholders (key informants) from states, LGAs, and communities were selected, based on information provided by the state governments, and featured the chairs of the State Civil Service Commission and State Local Government Service Commission, state NPHCDA directors, LGA PHC coordinators and personnel directors, in addition to the PHC Department, Supervisory Counsellor for Health, physicians, the Head of Midwifery Service Scheme (MSS), heads of village development committees, and representatives from donor-funded health care development programs such as USAID TSHIP.

\section{SAMPLING PROCEDURE}

\section{Stage 1: Selection of LGAs}

The list of LGAs in Bauchi and Cross River states was separated into urban and rural categories.

\section{Stage 2: Selection of PHC Facilities Within LGAs}

After LGAs in each state were stratified into urban and rural in consultation with the SMoH and State Primary Health Care Development Agency (SPHCDA), a random selection of two LGAs per state (Alkaleri and Giade LGAs in Bauchi, and Yala and Etung LGAs in Cross River) from the list of rural LGAs in each State by balloting. A list of PHC facilities (health posts, clinics, centers) offering MNCH services in the two selected LGAs in each state were obtained from the SPHCDA. To ensure equal representation of the different types of facilities, proportionate and simple random sampling using the table of random numbers was used in selecting 50 percent of the different facility types.

\section{Stage 3: Selection of FLHWs, Clients, and Household Heads}

The head of each facility was identified by LGA and SPHCDA officials and were selected for interviews. Facility heads in turn identified all available FLHWs in their facilities, who were confirmed via the duty roster. All staff on the lists were selected except those on leave, sick, or traveling during the data collection process. Women service users (clients) who sought $\mathrm{MNCH}$ services for themselves or their children in the selected PHC facilities during the defined period of time were contacted outside facility premises. Consent was obtained from each woman, for herself or for her child or children, after which respondents were subsequently interviewed. Communities within the catchment areas of PHC facilities were randomly chosen. After randomly selecting the first house for surveying, interviewers stopped at every third house until the required number of households for that community was fulfilled. The head of a selected household was then interviewed.

Key stakeholders were purposefully selected following consultation with state and LGA officials in Bauchi and Cross River, as well as by Population Council Nigeria staff. 


\section{DEVELOPMENT OF KEY INSTRUMENTS: KEY INFORMANT GUIDE AND SURVEY QUESTIONNAIRES}

Development of the qualitative and quantitative tools was informed by issues and indicators related to the research questions and objectives. Details of the instruments, type of design, issues addressed in each tool, and type of respondent are provided in Table 1.

Table 1: Study Instruments, Participants and Issues Addressed in Each Instrument

\begin{tabular}{|c|c|c|c|}
\hline $\begin{array}{l}\text { Type } \\
\text { of Instrument }\end{array}$ & $\begin{array}{l}\text { Study } \\
\text { Design }\end{array}$ & $\begin{array}{l}\text { Type } \\
\text { of Respondent }\end{array}$ & Issues Addressed \\
\hline $\begin{array}{l}\text { Facility } \\
\text { Mapping } \\
\text { and Inventory } \\
\text { Questionnaire }\end{array}$ & Quantitative & Facility Head & $\begin{array}{l}\text { Building and infrastructure; facility infrastructure } \\
\text { and amenities; review of last six months' } \\
\text { activities; pregnancy outcomes; Pregnancy } \\
\text { complications; immunization; child health; } \\
\text { health commodity status and distribution; } \\
\text { material inputs and supply (equipment and } \\
\text { materials) etc. }\end{array}$ \\
\hline $\begin{array}{l}\text { FLHW } \\
\text { Questionnaire }\end{array}$ & Quantitative & FLHW staff & $\begin{array}{l}\text { Section 1: Socio-demographic characteristics, } \\
\text { working conditions; } \\
\text { Section 2: Knowledge of government ascribed } \\
\text { roles in PHC; knowledge of critical MNCH } \\
\text { contents; } \\
\text { Section } 3 \text { : Equipment a n d s u p p I i e s, } \\
\text { s u p e rv i i i n, record keeping, community } \\
\text { support, barriers and facilitators facing FLHWs } \\
\text { in MNCH service delivery; Best performed MNCH } \\
\text { roles. }\end{array}$ \\
\hline $\begin{array}{l}\text { Client Exit } \\
\text { Questionnaire }\end{array}$ & Quantitative & $\begin{array}{l}\text { Women clients } \\
\text { using MNCH } \\
\text { services } \\
\text { in PHC facility } \\
\text { for them- } \\
\text { selves } \\
\text { or children }\end{array}$ & $\begin{array}{l}\text { Socio-demographic data, types of } \mathrm{MNCH} \\
\text { services sought, type of health worker seen }\end{array}$ \\
\hline $\begin{array}{l}\text { Household } \\
\text { Questionnaire }\end{array}$ & Quantitative & Household Head & $\begin{array}{l}\text { Socio-demographic information, house hold } \\
\text { assets, reported illnesses among women, } \\
\text { under-five children, and newborns in the last } 12 \\
\text { months; reported deaths and causes } \\
\text { among women, children under five years old, } \\
\text { and children born in the six months prior } \\
\text { to the interview }\end{array}$ \\
\hline $\begin{array}{l}\text { Key informant } \\
\text { interview guide }\end{array}$ & Qualitative & $\begin{array}{l}\text { Health } \\
\text { policymakers, } \\
\text { managers, } \\
\text { and service } \\
\text { providers } \\
\text { at state } \\
\text { and community } \\
\text { levels }\end{array}$ & $\begin{array}{l}\text { Opinion on health status of women and } \\
\text { children in rural areas, problems facing FLHWs } \\
\text { and their performance and whether there is a } \\
\text { place for new mid-level cadre in the present PHC } \\
\text { personnel structure }\end{array}$ \\
\hline
\end{tabular}




\section{PREPARATION FOR DATA COLLECTION}

\section{Instrument Validation}

Household and client exit instruments for data collection were originally developed in English, and translated to Hausa and a pidgin language, respectively, for use in Bauchi and Cross River states. They were back-translated to English to ensure accuracy, after which the questionnaires were converted to an internet-based questionnaire and downloaded to mobile android phones for use during field work.

\section{FIELD WORK}

Initial key informant interviews (KIIs) took place between 9 and 13 November 2015, while survey interviews were between 1 and 17 August 2016 in the two states.

Consultations with local authorities, and principal opinion and community leaders, preceded the study, to inform them of the study's objectives, as well as seeking their approval and support. Before entering any facility or community, information was provided to them by Population Council's state study coordinators. Klls were conducted with health program stakeholders in both states.

Interviews with heads of selected facilities (heath posts, clinics, PHC centers, comprehensive health centres), who were previously notified, were conducted with the facility questionnaire. After this, facility heads provided a list of their staff comprised of the cadres of interest (nurses, midwives, CHOs, SCHEWs, JCHEWs), who were all subsequently interviewed using the FLHW questionnaire.

Women who attended the PHC facilities and obtained $\mathrm{MNCH}$ care either for themselves, newborn, or under-five children were interviewed outside facility premises using the client exit questionnaire. Interviews with heads of households, using the household questionnaire, were in catchment areas previously grouped around the PHC facility. A household was defined as a group of people who eat their meals prepared from the same cooking pot.

The survey data, collected on android smartphones, were submitted to the data server upon completion of each survey interview and checked by supervisors.

\section{DATA QUALITY CONTROL}

Supervisors made random checks of completed questionnaires while research assistants and data collectors were in the field, and any irregularities were corrected. S upervisors reviewed each completed questionnaire in the evenings after daily review meetings before sending the data collected to the database. The summary of data collected is shown in Table 2.

Table 2: Numbers of Health Facilities, FLHWs, Clients, and Households Interviewed

\begin{tabular}{|l|l|c|c|c|c|}
\hline \multirow{2}{*}{ State } & LGA & $\begin{array}{c}\text { Number of Health } \\
\text { Facilities Visited }\end{array}$ & $\begin{array}{c}\text { Number of FLHWs } \\
\text { Interviewed }\end{array}$ & $\begin{array}{c}\text { Clients } \\
\text { Interviewed }\end{array}$ & $\begin{array}{c}\text { Households } \\
\text { Visited }\end{array}$ \\
\hline \multirow{2}{*}{ Bauchi } & Alkaleri & 15 & 27 & 49 & 366 \\
\cline { 2 - 6 } & Giade & 11 & 22 & 59 & 321 \\
\hline \multirow{2}{*}{ Cross River } & Etung & 10 & 15 & 41 & 223 \\
\cline { 2 - 6 } & Yala & 30 & 50 & 107 & 638 \\
\hline Total & & 66 & 114 & 256 & 1,548 \\
\hline
\end{tabular}




\section{DATA PROCESSING AND ANALYSIS}

\section{Quantitative and Qualitative Analytical Framework}

\section{Quantitative}

Each questionnaire was given a unique identification number that specified the LGA where the data were collected and type of survey questionnaire. Data files were checked to ensure that appropriate numbers of records were entered for each activity. Checks for errors were made, with corrections as necessary. Since the study's objective is assessing FLHWs, they consitutue the unit of analysis, and/or the facilities where they work. Descriptive statistics summarize the data, with results presented in frequency tables with percentages and/or mean.

To provide answers for the question of what are the disease burdens of women and children in communities served by FLHWs, the proportion of reported illnesses and deaths among women of reproductive age (WRA), children less than five years of age, and children born six months preceding the survey by household heads were summarized using descriptive characteristics.

To elicit FLHWs' knowledge of their prescribed PHC roles, only those of CHEWs and JCHEWs' were assessed due to their significant proportion, for planning and organizing maternal health, health education and counseling, community mobilization, and provision of integrated PHC services and ANC, etc.

To provide an answer to the question, "What is the level of FLHWs' knowledge of critical MNCH content that can affect their performance?", their knowledge of critical MNCH content, for ANC counseling, danger signs and complications in pregnancy, management of delivery, and child health problems were measured and scored on a 13-point scale, with one point allocated for each correct answer. Scores were categorized and ranked as Poor, Good, or Excellent. FLHWs who scored 11 and above were classified with Excellent knowledge of critical MNCH content, those who scored between 8 and 10 were classified with Good knowledge, while those scoring 7 and below were classified with Poor knowledge of MNCH content. Considering the limited numbers of nurses and midwives, these cadres were added to the "other" category.

To answer the question, "What MNCH services are performed by FLHWs and how satisfied are the users of MNCH services provided by FLHWs at PHC facilities (clients)?", the demographic characteristics of FLHWs dichotomous indicators depicting gender, age (25 to 29, 30 to 34,35 to 39,40 to 44 age brackets), and professional cadre (JCHEW, CHEW, CHO, "other" i.e. nurse or midwife) were used. FLHWs' self-reported performances were based on their provision of FP, ANC, assisted delivery, facility referrals for delivery, $\mathrm{PNC}$, newborn care, vaccination, nutrition, and treatment of malaria.

To identify factors (personal, organizational, community) influencing FLHWs' MNCH services, personal factors determing their work as FLHWs, motivations to work, satisfaction with job performance, and opportunities to use acquired skills were solicited and summarized. Availability of equipment, materials, and amenities needed by FLHWs for $\mathrm{MNCH}$ services, and infrastructural defects, were also summarized along with community factors including support from PHC development committees.

\section{Qualitative}

Stakeholders' opinions of rural women's and children's health statuses, problems facing FLHWs, FLHWs' performance, and whether a new mid-level FLHW cadre is warranted were based on information from KIIs. Information generated was transcribed after field work. Qualitative data were organized and coded. Using Atlas Ti. software, content analysis identified emerging themes and sub-themes. Narratives were subsequently constructed for stakeholders' views for a better understanding of their opinions and perceptions. 


\section{ETHICAL CONSIDERATIONS}

Permission was sought and granted by four separate ethical review boards: Bauchi state's Research Ethics Committee, Cross River state's Research Ethics Committee, the University of Ibadan University College Hospital (UI/UCH) Ethics Committee, and Population Council's Institutional Review Board (IRB) in New York. In addition, permission was solicitied and provided by local, state, LGA, and community officials after visiting them and explaining the study's objectives and procedures. The study was conducted according to the ethical guidelines and principles of confidentiality, beneficence, and voluntariness. Informed consent was obtained from each respondent prior to commencing an interview for the study. 


\section{Findings}

\section{MATERNAL, NEWBORN AND CHILD DISEASE BURDEN IN COMIMUNITIES SERVED BY FLHWs}

\section{Maternal Newborn and Child Disease Burden in Communities Served by FLHWs}

The results of household interviews reflect the maternal newborn and child disease burden within communities for reported illnesses and deaths among women and children.

\section{Reported IIInesses Among Women in Households}

Overall, about 804 (31.6\%) of the 2,544 women reported illnesses related to pregnancy and childbirth in the 12 months prior to the survey. As shown in Table 3, the most reported illnesses were "other diseases" (Bauchi 48.45\%, Cross River 62.44\%), "shortage of blood" (Bauchi 4.89\%, Cross River 1.65\%) and "convulsion in pregnancy" (eclampsia) (Bauchi 5.22\%, Cross River 0.16\%). Respondents are likely to have reported most illnesses among "other diseases" because of their inability to properly identify them. More of the women (41.4\%), however, were taken to a PHC center (comprehensive center and health post) for treatment in Bauchi, and about a third to chemist shops (33.3\%) in Cross River. Slightly more than half of respondents said that patients fully recovered after treatment (Bauchi 58.4\%, Cross River 58.3\%), and a majority expressed satisfaction with the outcome (Bauchi 91.5\%, Cross River 69.4\%).

\section{Reported IIInesses of Newborns and Under-Fives at Household Level}

Among the various diseases reported for newborns in the prior 12 months, watery stool (Bauchi 36.5\%, Cross River 10.9\%) was reported most. Patients with diseases were taken to about a fifth of PHC centers in both states (Bauchi 22.4\%, Cross River 18.5\%). About a third reportedly recovered after treatment (Bauchi 29.8\%, Cross River 33.2\%) and more than half of the respondents in Bauchi (55.6\%) and a third in Cross River (39.3\%) expressed satisfaction with the outcome of treatment (Table 4a).

Fever was the most frequently occurring illness among children under the age of five years (Bauchi $55.6 \%$, Cross River $49.8 \%$ ), followed by cough with catarrh (Bauchi $24.8 \%$, Cross River $37.0 \%$ ), and watery stool (Bauchi, 17.8\%; Cross River 10.8\%). PHC centers in Bauchi (29.5\%) and patent medicine vendors in Cross River (28.3\%) were used fairly often for the treatment. More than half (56.2\%) of under-five children in Cross River and 40.6 percent in Bauchi were "fully recovered" after treatment. About two thirds of respondents in Bauchi and Cross River (66.2\% and 62.4\%, respectively) expressed satisfaction with treatment outcomes (Table 4b).

\section{Reported Deaths Among Women in the Last Six Months}

A total of 64 deaths among 2,544 women in the prior six months were reported, of which 53.1 percent and 46.9 percent, respectively, were from Bauchi and Cross River. Primary causes of death were reported as "wish of God" (38.2\%) in Bauchi and "diseases" (46.7\%) in Cross River. Reasons attributed to the deaths were "inadequate attention and care by health workers" in Bauchi $(41.2 \%)$ and 'spiritual attacks' in Cross River (73.3\%) (Table 5a).

\section{Reported Deaths of Newborns and Under-Five Children}

As depicted in table 5b, of the 79 reported deaths among 657 newborns in the last six months, 67.1 percent and 32.9 percent were in Bauchi and Cross River, respectively, and the causes of deaths were mainly attributed to "unknown causes" (Bauchi 41.5\%, Cross River 30.8\%). A majority reported the deaths as the "wish of God" (Bauchi 88.7\%, Cross River 38.5\%). 
Table 5a (Appendix) shows, of the 111 reported deaths among the under-fives in the last six months, a higher proportion in Bauchi (81.1\%) than in Cross River (18.9\%). Fever was a highly reported cause of death (Bauchi 64.4\%, Cross River 52.4\%), followed by watery stool (Bauchi 17.8\%, Cross River 19\%). "Wish of God" (Bauchi 85.6\%, Cross River 33.3\%) was reported as the primary cause of death.

Results from stakeholders' interviews give credence to household head opinions of the health status of women and children in rural areas, with many respondents in both states saying it was fair but improving. A senior government official in Cross River stated:

"Generally speaking, the health status of women and children in the state, now, is below average ...in some places the terrain is so bad, some of these places you will see a lot of health posts without the basic infrastructure and resources needed to make them functional. You will find out that the health posts are there, but they don't have what it takes to be effective and efficient."

A Bauchi government official said:

"The status of women across the state, although I may not have documentary evidence to show, but I will personally say, their health status is fair."

Most participants in Cross River felt that women's health is improving, due to interventions and programs from both federal and state governments, non-governmental organizations, as well as developmental partners. According to a SMoH official:

"It used to be very poor, but the situation is improving because of several government programs to improve maternal and child health. Many programs such as midwives service scheme and efforts of the state government through the health centers have contributed to the improvement."

The head of a health training institution commented:

"In my own opinion, the state government has tried or is trying."

Participants in both states identified malaria, malnutrition, anemia in pregnancy, and worm infestation as the major diseases putting women's health at risk in rural areas. A senior health care administrator in Bauchi stated:

"The first one, I think, is malaria, secondly, it has to do with malnutrition-malnutrition because they don't have the opportunity to take the required balanced diet, especially the pregnant women..."

A human resource official in Cross River remarked:

"For me, its pregnancy and its complications, i.e. anemia in pregnancy, diabetes in pregnancy, malaria in pregnancy...and these result to complications during delivery, e.g. obstructed labor; malaria, infectious diseases such as HIV, and non-communicable diseases such as hypertension are on the rise."

Stakeholders in general agreed on common conditions affecting newborns such as malnutrition, malaria, measles, diarrhea, gastroenteritis, and pneumonia, as major factors in newborn illness and death.

"Common health diseases and illnesses among newborn and children include malnutrition, malaria, measles, diarrhea or let me say gastroenteritis." Head of Health Training Institution, Bauchi

"Of course, there is pneumonia, as many people are not aware of how to keep their baby away from cold, there is also malaria and to some extent anemia." Chair, CHW organization, Bauchi

"Newborns sometimes present with tetanus and sometimes with jaundice and anemia due to poor cutting of the newborn cord." Retired government officer, Cross River

It was generally opined that the same type of diseases that affect newborns also affect under-five children. 


\section{FRONTLINE HEALTH WORKERS' KNOWLEDGE OF THEIR PRESCRIBED PHC ROLES AND MNCH CRITICAL CARE THAT COULD AFFECT THEIR PERFORMANCE}

\section{FLWHs' Socio-Demographic Characteristics}

Table 6 (Appendix) summarizes the FLHWs socio-demographic characteristics. A total of 114 FLHWs delivering PHC services in the PHC facilities were enrolled in the study, with slightly more in Cross River (57\%) than in Bauchi (43\%). Overall, more FLHWs were female (58.8\%), but inter-state comparisons show more males in Bauchi (65.3\%) while females predominate in Cross River (76.9\%). Generally, analysis by professional cadre shows more (46.5\%) CHEWs followed closely by JCHEWs (44.7\%). Nurses (0.9\%) and midwives (1.8\%) working in PHC in both states were scant, and thus are classified as "other" in this report (see Table 6). Most FLHWs in Bauchi were in the 30 to 34 year old age bracket (34.7\%), while those ages 35 to 39 predominate in Cross River (27.7\%). Overall, most FLHWs (54.4\%) are working in PHC centers rather than PHC clinics or health posts. Cross River has slightly more JCHEWs and CHEWs than Bauchi.

\section{FLHWs' Knowledge of Their PHC Roles}

As shown in Table 7 (Appendix), the overall knowledge of roles expected from CHEWs and JCHEWS for health education and counseling, community mobilization, child health services, record keeping and documentation, among others was high except for the knowledge of planning and organizing maternal and child health programs. Overall, the proportion of CHEWs with good knowledge of their expected roles was higher than among JCHEWs. Interstate differences show JCHEWs in Cross River with slightly more knowledge than those in Bauchi state.

\section{Knowledge of Critical Maternal and Newborn Care Content}

Table 8 (Appendix) presents all FLHW cadres' knowledge of critical MNCH content for ANC, counseling, pregnancy symptoms, danger signs and complications, management of delivery, and child health problems. On average, the knowledge on these critical life-saving maternal and newborn interventions was relatively high, as most (70\%) FLHWs had excellent scores. More FLHWs (78.1\%) had excellent grades in Cross River than in Bauchi (58.7\%), while more CHEWs performed better (Bauchi 85.7\%, Cross River 90\%) than JCHEWs (Bauchi 34.8\%, Cross River 64.3\%). As shown in Table 8, Bauchi has the higher proportion of FLHWs with poor knowledge of essential $\mathrm{MNCH}$ content, with about 20 percent scoring 7 or below (out of 13), when compared with Cross River's 3.1 percent.

\section{FLHWs' PROVISION OF CRITICAL, LIFE-SAVING MATERNAL AND NEWBORN INTERVENTIONS}

\section{FLHWs' Self-Reported Performance of MNCH Services}

Average number of clients seen by different FLHW cadres: Daily, FLHWs in Bauchi attend more clients than FLHWs in Cross River. Generally, CHEWs attend more clients in both states than JCHEWs. When assessing interstate differences, average daily clients attended by CHEWs in Bauchi $(n=21)$ are three times those attended by CHEWs in Cross River (7), and similarly observed among JCHEWs (Bauchi 16, Cross River 5).

Infant deliveries by FLHWs: Overall, in the six months preceding the survey, 50 percent of all deliveries in boths states were by CHEWs, followed by JCHEWs (Bauchi 30.6\%, Cross River 25.9\%) and "other" (Bauchi 30.6\%, Cross River 25.9\%). Only a small proportion of CHOs (Bauchi 2.5\%, Cross River 20.7\%) assisted with deliveries. 
Client referrals by FLHWs: As shown in Table 10 (Appendix), during the six months prior to data collection most FLHWs refered clients. Most JCHEWs (90.2\%) referred clients and completed referral forms (88.2\%); similarly, most CHEWs referred clients (84.9\%) and completed referral forms (79.2\%). The proportion of CHEWs who received responses from the referred facilities was higher $(66 \%)$ than for JCHEWs (52.9\%). FLHWs in PHCs and health clinics provided more client referrals (PHCs 96.4\%, clinics 94.7\%) and completed more referral forms (PHC 91.9\%, clinic 80\%), compared to referrals by FLHWs in health posts $(90.6 \%)$ and their completed referral forms $(68.8 \%)$ (Table 10). State variations show more JCHEWs in Cross River (57.1\%) than in Bauchi (45.8\%) with responses from referral facilities, with more CHEWs receiving referral responses in Cross River (80\%) than in Bauchi (50\%) (Table 11, Appendix).

Home visits by FLHWs: FLHWs were asked to indicate their numbers of community home visits for $\mathrm{MNCH}$ services in the six months prior to data collection. While 1,548 households were part of the study, respondents indicated only 114 home visits by FLHWs in the preceding six months, with 81.6 percent of FLHWs visiting one to 20 households during the period (Table 12, Appendix).

FLHWs' MNCH proficiency: FLHWs were asked to indicate the $\mathrm{MNCH}$ tasks at which they are most proficient. Excluding $\mathrm{CHOs}$ and "others" because of their small numbers, more JCHEWs reported proficiency in managing childhood diseases (Bauchi 45.5\%, Cross River 40\%), while CHEWs more often indicated ANC (Bauchi 43.5\%, Cross River 40\%).

FLHW comfort in performing MNCH activities in national task shifting and -sharing policy: When asked about their comfort in performing activities in the national task shifting and -sharing policy, more than 80 percent of FLHWs indicated comfort with ANC, labor and delivery, immediate PNC, PNC, immediate newborn care, and FP, while less than half are uncomfortable sending and receiving CD4 laboratory tests, providing couples with counseling and HIV testing, routine screening tests, especially for HIV, calculating expected dates of delivery, assessing the needs of women and their families, and physical examination. It is difficult to ascertain, however, the proportion of FLHWs who can effectively perform tasks from other cadres without the requisite competency-based training mandated by the task shifting and -sharing policy.

General output data on MNCH services provided by FLHWs: Data from facility record reviews show 1,857 clients provided $\mathrm{MNCH}$ services by FLHWs in the two states during the six months preceding data collection (Bauchi 937, Cross River 920). Overall, FLHWs saw more clients for childbirth and child care (Cross River 510, Bauchi 269), followed by postpartum and PNCH services (Cross River 565, Bauchi 269). The fewest patients were provided ANC services (Cross River 92, Bauchi 43).

Nearly three times the number of long-lasting insecticide nets (LLINs) were distributed in Cross River $(n=11,683)$ by FLHWs than in Bauchi $(4,711)$ during the same period. FLHWs in Bauchi distributed 12 times more oral rehydration salts (ORS) sachets $(2,119)$ than in Cross River $(169)$, and Bauchi FLHWs provided 573 infants ORS in PHC facilities, compared to 158 in Cross River.

\section{STAKEHOLDER OPINIONS OF FLHW PERFORMANCE}

Stakeholder opinions of FLHW impacts were mostly favorable, with most interviewed stakeholders stating that FLHWs have contributed to reducing illnesses and deaths among rural mothers and children. Participants from both states cited examples of informal observations of FLHWs working in PHC facilites in addition to formal reports. A majority pointed out that, for the past few years, incidences of illnesses and deaths have decreased drastically. A high ranking civil servant from Bauchi stated:

"They have reduced the incidence of maternal, newborn and child diseases. If ten people used to die in a year before, you may find less than three dying now because of their intervention."

Some other respondents attributed the decline in illnesses and deaths of children under the age of five years to the vaccinations given them. According to a government official from Cross River:

"They are all performing well, especially in immunization, because they [health workers] enter everywhere." 
Another senior official remarked:

"I would say their performance has reduced morbidity and mortality among newborn and even the under-fives because immunization services at health centers appear to be taken very seriously. And you now see that you don't have many of these childhood diseases because parents ensure that children under their care complete their immunization..."

\section{FACTORS AFFECTING FLHW PERFORMANCE}

\section{Facilitating Factors}

Personal factors reportedly influence FLHWs' MNCH services, including their personal attributes. Overall, a majority of FLHWs are content serving their community (Bauchi 100\%, Cross River 98.5\%), are personally motivated to serve (Bauchi 95.9\%, Cross River 92.4\%), satisfied with their job performance (Bauchi 95.9\%, Cross River 93.9\%), and excited by the opportunity to use their skills (Bauchi 95.9\%, Cross River 98.5\%).

Organizational factors were described by FLHWs as affecting their performance. Most FLHWs claimed that their $\mathrm{MNCH}$ training within the last five years prepared for their service provision and contributed highly to their job performance. PHC facilities' 24-hour operating hours enable FLHWs' services, with most FLHWs in Cross River (90\%) and Bauchi (60\%) reporting that this motivates them to spend more time at work, beyond the stipulated 40 hours per week.

Findings from IDIs with stakeholders on factors perceived as influencing FLHWs' MNCH performance provided additional information, with some study participants stating that better staff monitoring, improved tracking tools, and better working environments can enhance FLHW performance. A community leader from Cross River stated:

"One of the facilitating factors...is that monitoring is better, and tracking has improved and the tools for tracking is there for everyone...they use mobile telephones!"

Another non-governmental official from Bauchi added:

"I can say that what is contributing to improved performance by health workers is the conducive working environment."

Community factors facilitating FLHWs' performance are manifested through support to them and their facilities by community village and ward development committees. As presented in Table 13 (Appendix), more than one third of CHEWs and JCHEWs reported support from village and ward development committees, whch enhanced their job performance, in sharing knowledge on $\mathrm{MNCH}$ care (CHEWs $44.1 \%$, JCHEWs $46.2 \%$ ), and community mobilization, for influencing community members' use of PHC facilities (CHEWs 46.3\%, JCHEWs 45.3\%), and record keeping assistance (CHEWs 48.8\%, JCHEWs 42.5\%).

\section{Inhibiting Factors}

Personal factors inhibiting FLHWs' performance begini with their insufficient knowledge of critical MNCH content, for ANC, counseling, danger signs and symptoms of pregnancy, complications in pregnancy, management of delivery, and child health difficulties.

Organizational factors inhibiting FLHWs' performance (shown in Tables 14 and 15, Appendix) include stock outs of equipment and materials needed for $\mathrm{MNCH}$ service, along with sub-optimal staff welfare. Over 40 percent of CHEWs in both states (Bauchi 50\%, Cross River 46.7\%) reported no availble fetoscopes, and for 44 percent and 25 percent of JCHEWs in Cross River and Bauchi, respectively. Thermometers were unavailable for more than one third of all CHEWs (Bauchi 40.9\%, Cross River 43.3\%) and half of Bauchie's JCHEWs (Cross River 20\%). Weighing scales were unavailable to 40.9 percent of CHEWs in Bauchi and 56.7 percent in Cross River, as well as 58.3 percent and 36 percent, respectively, 
of JCHEWs in Bauchi and Cross River. Stethoscopes were unavailable to around one third of CHEWs in both states (Bauchi 31.8\%, Cross River 40\%). More than one third of CHEWs (40.9\%) and half of JCHEWs (50\%) in Bauchi experienced absent blood measuring apparatuses (sphygmomanometer), while results were better in Cross River for CHEWs (20\%) and JCHEWs (24\%). Tables for gynecological examination were unavailable for use by about a third of CHEWs in both states (Bauchi 31.8\%, Cross River 36.7\%).

Delivery couches were unavailable when needed to 46.7 percent of CHEWs and 44 percent of JCHEWs in Cross River, as well as 22.7 percent of CHEWs and 33.4 percent of JCHEWs in Bauchi. Thirty percent of CHEWs in Cross River reported non-availability of delivery kits when needed. Cool boxes for storing vaccines at required temperature were unavailable to 31.8 percent of CHEWs and 45.8 percent of JCHEWs in Bauchi, and 30 percent of CHEWs and 40 percent of JCHEWs in Cross River. Misoprostol (approved by FMoH for PHC use) was unavailable for 22.7 percent of CHEWs and 25 percent of JCHEWs in Bauchi, and 30 percent of CHEWs and 32 percent of JCHEWs in Cross River.

About one third of JCHEWs had no regular access to a water supply (Bauchi 29.2\%, Cross River 28\%) or a generator (Bauchi 25\%, Cross River 28\%). Similar findings were reported for CHEWs' access to a water supply (Bauchi 36.4\%, Cross River 33.3\%) and generator (Bauchi 40.9\%, Cross River 30\%). Direct observation of facilities showed, overall, a substantial proportion in a state of disrepair, with leaking roofs (Bauchi 76.9\%, Cross River 45\%), cracked floors (Bauchi 57.7\%, Cross River 50\%), and broken doors and windows (Bauchi 57.7\%, Cross River 42.5\%) (see Table 16, Appendix).

Poor staff welfare was also identified as a barrier to FLHW performance. When FLHWs were asked about major welfare challenges affecting their $\mathrm{MNCH}$ responsibilities, more than half of JCHEWs (Bauchi $79.2 \%$, Cross River 60.7\%) and CHEWs (Bauchi 54.5\%, Cross River 73.3\%) identified delays in salary payments as a major welfare challenge (Table 17).

Stakeholders identified numerous barriers affecting FLHWs' effective MNCH services. Most participants had concerns about FLHWs' remuneration, housing, transportation, clean and drinkable water, school facilities for their children, and working equipment.

"The condition of service is not favorable in terms of housing, salary, transportation, availability of clean water, availability of schools for the children. If you have those you will give your best, but if not you will not." Senior civil servant, Bauchi

"In our rural communities, there is no electricity, no accommodation, and poor housing. These can have a demoralising and depressing effect on staff morale." Training officer, Cross River

"Where there are no drugs, and where there is no accessibility of roads to get to the rural community on time...these hinder service delivery." Mid-level civil servant, Cross River

A few participants expressed concerns about inadequate staffing, which, to them, has been a constant problem over the years in rural areas. According to a school head in Bauchi:

"Inadequate staffing is a problem, because one person cannot stay for 24 hours in the hospital; that is a major factor."

Another reported inhibiting factor is the effect of cultural norms and practices. Concerns abound about gender-based preferences for health care providers at PHC facilities. Survey data reveal that, out of 256 exit clients who accessed $\mathrm{MNCH}$ services and were enrolled in the study during the data collection period, only six (2.3\%) respondents reported preferring a male FLHW for $\mathrm{MNCH}$ services, while 113 (44.1\%) preferred a female, and more than half, 137 (53.5\%), reported no gender preference. When asked who had actually provided services at the health facility, $68(27 \%)$ reported being attended to by a male FLHW while $188(73 \%)$ reported being attended to by a female. When state variations were considered, lack of FLHW gender preference was greater in Cross River (63.5\%), in southern Nigeria, than in Bauchi (39.8\%). Preference for a female FLHW was higher in Bauchi (59.3\%) than in Cross River (33.1\%). Preference by female clients for male FLHWs was low in both study states. 


\section{STAKEHOLDER OPINIONS OF FLHWs' PHC MNCH ROLES AND PERFORMANCE}

Health care system stakeholders in both states believe FLHWs are essential, especially for the care for women and children, and should provide much-needed health care services such as ANC, immunization, child de-worming, diagnosis, and treatment of illness in rural areas.

"[Frontline health workers] are the first point of contact in the community, they are supposed to attend to what they can and refer." Head of Health Training Institution, Bauchi

Those interviewed noted that $\mathrm{CHWs}$ are expected to spend substantial time in the community, providing preventive care as well as significant time at PHC faciltiies providing clinical curative services.

"CHEWs are to spend 60 percent of their time in the health facility...40 percent of their time in the community. The JCHEW is to spend 80 percent of his time in the community while 20 percent in the facility." Local Government Health Official, Bauchi

Another key FLHW role mentioned is community mobilization:

"There is the issue of mobilizing for JCHEWs, JCHEWs can mobilize pregnant women from the communities to go to the clinics for ANC." Head of Community-based organization, Bauchi

Most participants were able to mention at least one expected $\mathrm{MNCH}$ role for midwives and nurses. It was emphasized that midwives are tremendously important in $\mathrm{MNCH}$ services but there are not enough in PHC system, and the few available are not willing to remain in rural areas and communities.

"The midwives are to take charge of all the maternity clinics and are to provide antenatal care services, postnatal care services, conduct deliveries, family planning; they even do home visits." PHC Coordinator, Bauchi LGA

Most study participants interviewed mentioned that at local government health facilities CHOs are the facility heads. CHOs at the PHC level are expected to supervise CHEWs, JCHEWs, as well as nurses and midwives.

It was suggested that JCHEWs and CHEWs were introduced to bridge gaps identified in PHC human resources. Most participants opined that these categories of health care providers have been trained to identify cases needing simple medication, treat such cases, and refer those beyond their care competencies. Some respondents were not comfortable with $\mathrm{CHWs}$ handling deliveries, even though they acknowledge that there are not enough midwives at the PHC level.

"If there are no midwives, the $\mathrm{CHO}$ can attend to pregnant women, likewise the CHEWs and JCHEWs." PHC Coordinator, Bauchi LGA

When asked about MNCH functions best performed by FLHWs, immunization and ANC were mentioned most, although other $\mathrm{MNCH}$ services were mentioned.

"For the JCHEWs and CHEWs, anything that has to do with vaccination, immunization and the rest, they take part in these very well..." Senior MoH Official, Bauchi

Functions identified as least successfully executed by FLHWs were research, community mobilization, and PNC.

"The role they perform worst is that they don't do research." Head of Health Training Institution, Bauchi 


\section{STAKEHOLDER SUGGESTIONS FOR EXPANDING FLHWs' RURAL PHC MNCH SERVICES}

The broad consensus of participants is that increasing FLHW appointments in rural communities could be a catalyst for rapid $\mathrm{MNCH}$ health care expansion, bolstered by training institutions' reinforcement; there was also consensus among study participants in both states that FLHW pre-service training institutions need strengthening. According to a senior school head from Bauchi:

“The only available opportunity now is to scale up establishment of these front-line health workers' institutions like the college of nursing, to scale it up, so that it can become accredited and start producing as much [health workers] as possible, and we would have an adequate number of nurses and midwives."

Another school head from Cross River supported this:

"Government should really look at the training institutions of these FLHWs and ensure that those training institutions are well equipped with facilities, infrastructures and they have the right numbers of qualified tutors to train these people, otherwise they will be turning out people who are not well trained."

This was followed by the suggestion of training existing workers in activities in the task shifting policy, with a senior policy actor in Bauchi saying:

"The task shifting policy, if it is really put to use, it will greatly improve services."

Involving more private sector health care providers and integrating them within the health delivery system was suggested by a senior official in Bauchi as a viable means of expanding rural FLHW PHC MNCH services.

Most participants in Cross River would prefer links with TBAs, followed by their re-training and assimilation within the system. A program officer from Cross River stated:

"I will say that we should start forming linkages with the traditional birth attendants [TBAs] because some of them are experienced...if we can liaise with the TBAs, I think they can really expand the services that they are rendering at the community level."

For most participants in Cross River, such links are necessary because TBAs have been carrying out $\mathrm{MNCH}$ activities in rural communities but cannot perform optimally because they are not well trained. Although WHO is against the use of TBAs in health care service delivery, most respondents believed that retraining the TBAs would capacitate them with the needed skills and will go a long way in enhancing $\mathrm{MNCH}$ delivery in rural areas.

Other study participants mentioned that providing the necessary infrastructure and working tools will enhance the expansion of $\mathrm{MNCH}$ service delivery at PHC level in rual communities.

"Provision of ambulances, provision of vehicles for supervision of senior staffs [will be helpful]" Local Government Health Official, Bauchi

Strong community participation was identified as crucial:

“...for the community to be receptive to the services. Once a community health worker or health personnel is posted to the area, they should accept him, encourage him and give him all the necessary cooperation...the extent of cooperation they give normally helps in the delivery of services of such personnel." Senior Official in Ministry of Health, Bauchi 


\section{STAKEHOLDER OPINIONS OF A NEW FLHW CADRE FOR RURAL PHC MNCH SERVICES}

Stakeholder interviews show divided opinions on a potential new FLHW cadre for rural MNCH services. In Bauchi they tend to support a new FLHW cadre, stating that it would address PHC human resources shortages:

"If at all there is opportunity to do so, yes, it is necessary to create a new cadre, and this will make us to have additional staff so if they create another cadre [of health workers], it will be better."

This opinion was shared by many other Bauchi participants, including a senior administrative officer, who stated that such a strategy conforms to global health development:

"Since Nigeria is going with the global world, if there are innovations we cannot run away from it...I will also support [any such new innovation]...there won't be any opposition or resistance because we know there is problem on ground and the problem is lack of adequate manpower and these people will be trained so as to help assist in the healthcare delivery system..."

Many study participants in Bauchi said that potential benefits from a new cadre are further reductions in unnecessary illnesses and deaths in rural communities. One senior program officer remarked:

"The benefit is that it will reduce mortality and morbidity rates. If pregnant women come for ANC services, they will go home in good time and they will be served better with quality services."

Another health officer in Bauchi said:

"The benefits are that they will be posted to their rural areas, and they would be posted to their local government area, they will stay with the people, if there is any problem, they would be called upon to come and assist."

Most participants in Cross River oppose a new FLHW cadre, with most expressing strong reservations, stating that it would not solve the problem of inadequate manpower. According to a senior training officer:

“Well, presently, I don't think we need that...there is really no need to create a new cadre for health workers."

Although most Bauchi stakeholders support the idea of a new cadre, one senior civil servant from Bauchi's SMoH did not:

"If you create another cadre, they will do the same job [as existing cadres], and it may also be disadvantageous to the service."

The consensus of many study participants in Cross River is that a new cadre would lead to a duplication of existing cadres, creating enmity, disharmony, and opposition among existing professionals, and that the new cadre would be unable to optimally perform. Most Cross River respondents strongly recommended improving the skills of existing cadres instead of creating a new cadre. The head of a health training institution in Cross River remarked:

"We should look at improving the skills and the efficiency of the cadres we already have. If there are new innovations in the areas of maternal and newborn service delivery, they should try to introduce those new skills to the existing cadres and then equip them."

"Even the cadres we have are not doing the right thing...if you create another cadre, it will just be disaster." Staff member, development partner organization 


\section{Discussion}

The $\mathrm{MNCH}$ disease burden in communities where FLHWs work is of concern, given the numbers of women, newborns and under-five children who reportedly died within a six month period. Reported deaths were higher in Bauchi, with most household heads attributing them, among other reasons, to "inadequate attention and care by health workers," likely reflecting rural communities' growing frustration with the PHC system and poor availability of properly equipped PHC facilities in their communities. A previous study by the National Population Commission (2014) indicates higher maternal deaths in Nigeria's northern regions, which this study confirms.

\section{FLHW DEMOGRAPHICS AND MNCH KNOWLEDGE}

A key finding from this study is that only 114 FLHWs in the cadres of interest (nurses, midwives, CHOs, CHEWs, JCHEWs) were working in 66 PHC facilities-comprehensive health centers, PHC centers, clinics, and health posts-in the four selected LGAs of the two states. Of especial concern was the presence of very few nurses and midwives, reflecting an acute rural health workforce shortage for $\mathrm{MNCH}$ services. The government has seemingly failed to address PHC HRH shortages despite the availability of data revealing these shortages in prior studies. Research by NPHCDA in 2009 reported PHC worker shortages, which the present findings confirm-eight years later, without significant improvements. Gender distribution of health workers is skewed, with male FLHWs prevalent in Bauchi (in northern Nigeria) and more female FLHWs observed in Cross River (southern Nigeria).

Most FLHWs know their prescribed PHC MNCH roles but have knowledge deficits in critical MNCH content, especially ANC and counseling, danger signs, pregnancy symptoms and complications, management of delivery, and health care challenges for children. These knowledge deficits may constitute serious impediments to quality services for women and children who require skilled care to avert unnecessary deaths. These findings corroborate results from a study reported by FMoH (2014) showing that although about 70 percent of health workers had some basic, theoretical midwifery knowledge, only 31 percent could correctly assess fetal well-being, with 56 percent aware of routine tests for ANC. More troubling is that this $\mathrm{MNCH}$ content should have been acquired during these workers' pre-service training.

\section{FLHW PROVISION OF CRITICAL, LIFE-SAVING MATERNAL AND NEWBORN INTERVENTIONS}

A key finding from this study is that JCHEWs are are conducting infant deliveries in both states' surveyed rural PHC facilities. A likely explanation for this phenomenon are the inadequate numbers of nurses and midwives in rural health facilities. Infant delivery is definitively not part of JCHEWs' job description (Community Health Practitioners Registration Board of Nigeria 2006). In the absence of competencybased training and implementation of the new task shifting policy, JCHEWs are insufficiently skilled for managing deliveries and life-threatening pregnancy and childbirth complications. Experimenting with lifesaving procedures by these cadres, especially in complicated or difficult deliveries, could result in loss of life (FMoH 2014). This finding and its implications necessitate urgent implementation of the task shifting and -sharing policy. Future studies may need to ascertain the effects on quality of health care, as well as $\mathrm{MNCH}$ outcomes, of implementing the task shifting and -sharing policy; specifically, does task shifting for key $\mathrm{MNCH}$ roles, such as nurse and midwife delivery to other cadres such as CHEWs and JCHEWs, have an impact on quality of care and maternal mortality, especially in rural communities?

It is encouraging that most FLHWs refer clients to other facilities for advanced care, and complete necessary referral forms. This referral role and its execution by FLHWs observed in this study is commendable, preventing progression of actue illness and limiting complications and unnecessary death. 
Following their patient referrals, CHEWs received greater responses from the referral facilities, which could reflect the recognition placed on this cadre, in contrast to the diminished proportion of JCHEWs who received responses from referral facilities, which raises genuine concern. It is recommended that all higher level facilities to which clients are referred be re-trained on effective referral procedures and systems including the importance of responding with comments to staff and facilities providing referrals, for more effective referral processes and enhanced quality assurance in the health system.

It is apparent that JCHEWs are not effectively performing their community function of home visits, as only a small number of households were visited in the six month period. JCHEWs are expected to spend 80 percent of their working time within the community and 20 percent at health facilities (ibid). Their specific community functions include home visits to monitor pregnant women and children, identifying "at risk" members of the community, treating them, or referring them for treatment according to their standing orders, along with identifying care defaulters in the community and providing health education on environmental sanitation and prevalent health problems such as malnutrition, diarrhea, and sexually transmitted infections (STIs) (ibid). It appears that JCHEWs are engaged more in clinic-based functionsbeyond those prescribed by the Community Health Practitioners Registration Board of Nigeria, without requisite training nor the implementation of the task shifting policy-in both study states. This needs to be addressed as soon as possible in both states.

The fact that most FLHWs are comfortable performing $\mathrm{MNCH}$ tasks within the national task shifting and -sharing policy is noteworthy, suggesting that the policy is acceptable to FLHWs, who will be crucial for the policy's implementation and service delivery at the grassroots level. The few activities they identified discomfort in performing should be addressed during their training for task shifting implementation in both project states. Overall, CHEWs seem to perform most $\mathrm{MNCH}$ activities such as assisted delivery, ANC, and information, and counseling to pregnant women, which in accordance with their clinic-based functions.

More FLHWs in PHC centers and clinics were rated better than from other facilities such as health posts. It was hardly surprising, among all FLHW cadres, that CHEWs were rated high (excellent or highly satisfactory) by clients for MNCH services, followed by JCHEWs. The commendable performances of CHEWs and JCHEWs raise the issue of FLHW incentivization, specifically whether structured performancebased incentives will further improve PHC job performances and health outcomes in Nigeria. PHC center and clinic heads deserve similar motivation and incentives.

During the six month period prior to data collection, output data show only $1,857 \mathrm{MNCH}$ clients in the selected PHC facilities in the two states' four study LGAs. Significantly, the lowest numbers were recorded for ANC. A possible explanation is that pregnant women in rural areas are not utilizing PHC facilities either because of poor trust in service providers or poverty. Previous studies in Nigeria have shown poor ANC service utilization; according to the 2013 NDHS, only 18 percent of women had an ANC visit during their first trimester of pregnancy.

The high numbers of long-lasting insecticide nets (LLINs) during the same period are commendable.

\section{PERSONAL, ORGANIZATIONAL AND COMMUNITY FACTORS AFFECTING FLHWs' LIFE-SAVING MATERNAL AND NEWBORN SERVICES}

Personal motivation, along with community support from village and community development committees, are dual motivating factors revealed during this study that contribute to FLHW performance. Personal motivation should be increased through more incentive mechanisms encouraging their continued residence and work in rural areas. The finding related to development committees further justifies its presence in the Alma-Ata declaration. This finding is accordance with a study in Central Uganda that found that community participation influences CHWs' performance (Bagonza et al. 2014). 
FLHW performance is hindered mostly by system barriers, especially insufficient diagnostic equipment, materials, and amenities, in addition to weak infrastructure worsened by poor staff conditions. A triangulated synergy of these identified barriers by FLHWs, the household heads and the stakeholders probably suggest the strong impact of these challenges. It is unrealistic to expect excellent performance of the delivery of critical $\mathrm{MNCH}$ services when the facilities are poorly equipped, materials are insufficient, infrastructures are weak, salaries are delayed, incentives are low and discretion to reward good performance is missing. This finding reaffirms the results of past studies on system barriers affecting PHC workers' performance. A previous study by Josephat (2015) in Enugu state shows that existing equipment and manpower are negative factors influencing PHC implementation. It appears that not much action has been taken to improve the PHC facility functioning despite the mounting and consistent evidence (Nnebue et al. 2014, Musa and Ejembi 2004, Adeniyi et al. 2001) which policymakers and program managers should use to change the HRH dynamics within PHC settings. Stakeholders should also be taken on board as active partners in revitalizing the HRH situation in rural areas through for example active participation in facility health and ward development committees. This will increasingly ensure that community members bring both their experiences and opinions to address these identified barriers, especially through advocacy, resource mobilization, health care planning, and its implementation.

\section{IS THERE POTENTIAL FOR A NEW PRIMARY HEALTH CARE WORKER CADRE IN NIGERIA?}

The findings from stakeholders' opinions on the creation of a new cadre of FLHWs for MNCH services in rural PHC settings suggest the need for wider consultations for a consensus to then inform and influence policy actions. Stakeholders in Bauchi were more positively inclined towards the idea of introducing a new PHC worker cadre in Nigeria, in contrast to stakeholders in Cross River. Bauchi state recently introduced community midwifery within its health care delivery system, with understandable interest in any impact on MNCH outcomes. 


\section{Policy Implications, Conclusion and Recommendations}

\section{POLICY IMPLICATIONS}

The primary focus of this research study is generating evidence and providing essential information to improve HRH for Bauchi and Cross River states. This evidence and information will hopefully enable and support more effective delivery of $\mathrm{MNCH}$ services in these states. The major issues and policy implications emerging from this study include several domains.

The burden of maternal, newborn, and child morbidity and mortality in the study communities is high. Formative studies are needed to understand the reasons underlying poor PHC facility utilization. PHC policymakers should develop stakeholder partnership forums with traditional and religious leaders, village and ward development teams, CSOs, government representatives, and donor agencies for both producing and implementing a functional guide to deal with Nigeria's HRH challenge. There is need to learn more about best practices (possibly through study tours, among other direct interactions) with subsequent modeling in rural LGAs, with adequate staffing and resources, funded both by state governments and global bodies with a presence in Nigeria, such as WHO and UNICEF, among others.

Evidence of FLHWs' insufficient knowledge of essential life-saving $\mathrm{MNCH}$ content, which will continue to affect $\mathrm{MNCH}$ outcomes from PHC facilities, may likely reflect weaknesses and lapses in their pre-service training, and specifically their curricula, at training institutions. Competency-based training, specifically focused on $\mathrm{MNCH}$ knowledge gaps, should be approved by the government and its agencies. To ensure both FLHWs and health sector stakeholders in general take this seriously, results could be part of the criteria for FLHWs' job promotion. A long term solution could include institutionalization of effective inservice and continuing education mechanisms for health workers, as well as rapid integration of the recently revised $\mathrm{CHW}$ curricula at FLHW training institutions. There is also need to ensure that national and international conferences, where issues, best practices, and new innovations are discussed, are effectively and periodically organized in the country, and accessible to health managers and FLHWs, especially those providing MNCH PHC services.

FLHWs are confronted with many barriers inhibiting their optimal performance of MNCH service delivery. Policymakers should revisit the country's PHC policy and ensure compliance with a recommended minimum service package and infrastructure for each type of facility (NPHCDA 2007), in addition to a review of FLHWs' benefits. Funding conditionality could be used to ensure policy compliance by states and LGAs. Innovative funding mechanisms could provide opportunities and further promote effective service delivery, such as structured, performance-based incentive mechanisms. The present funding arrangement, whereby PHC facilities receive funds from LGAs, is ineffective, and a prior study found systemic disparities between between approved budgets and funds actually disbursed to to PHC facilities for items and equipment purchases (Adeniyi et al. 2004). A potential strategy is disbursing PHC funds directly, per LGA monthly allocation, FMoH to a fund managed by a board of private and public sectors including development partners. Such funds could also be used for FLHW incentives including accommodation, transportation, and allowances for rural workers.

\section{CONCLUSION}

More CHEWs are performing $\mathrm{MNCH}$ activities in rural $\mathrm{PHC}$ facilities, reinforcing the need for full task shifting policy implementation in variouis states' health systems-including Bauchi and Cross River. This study's findings reveal shortages of all FLHW cadres, along with insufficient equipment and materials essential for quality MNCH services. Poor staffing conditions exacerbate FLHWs' inadequate knowledge 
of critical MNCH content. Much is still needed to be done to improve HRH situation in rural Nigeria. The fact that FLHW performance is enhanced by active community involvement is noteworthy, however, and such involvement should be encouraged by government and other health sector stakeholders.

\section{RECOMMENDATIONS}

Based on the findings of this study, urgent actions are needed to:

- Increase the numbers and skills of FLHWs providing $\mathrm{MNCH}$ services in rural communities, especially nurses and midwives;

- Expand the number of health training institutions to escalate the training of FLHWs to meet minimum staffing levels for PHC facilities;

- Implement in-service MNCH competency-based training for FLHWs, to improve their knowledge of critical $\mathrm{MNCH}$ content and improve the quality of service delivery;

- Create enabling working conditions guaranting FLHWs' access to adequate and sustainable quantities of necessary supplies, and guarantee benefits including renumerations and incentives, with federal and state governments improving FLHW motivation and retention through adequate infrastructure, equipment, and drugs at rural health facilities in addition to sufficient employee remuneration;

- Introduce and properly implement structured, performance-based incentives for rural health workers;

- Enforce government policies and guidelines on minimum required equipment for PHC facilities; and

- Increase engagement of ward and village development committees, and empower their utilization of innovative approaches for community volunteers, for their efforts to complement the work of FLHWs at PHC facilities and in rural communities.

Implementing these recommendations will strengthen Nigeria's rural PHC system and improve FLHW performance.

\section{STUDY LIMITATIONS}

While this study makes substantial contributions to knowledge of $\mathrm{PHC}$ and rural $\mathrm{HRH}$, there are some key limitations worth mentioning. A major limitation, as reported, is that the numbers of PHC nurses and midwives (in both study states) are minimal, which limited the deductions about their performance from the study findings. Second, self-reporting by study respondents may have resulted in over- or under reporting, but to mitigate this, significant effort was made in effective training for interviewers prior to field work. In addition, assurances were provided to study respondents that no identifiers, by name or community, would be used when reporting, or during documentation, for the study. 


\section{References}

AbouZahr, C. 2003. Global burden of maternal death and disability. Br Med Bull 67: 1-11.

Adegoke, A.A., F. Atiyaye, A. Abubakar, A. Auta, A. Aboda. 2015. Job satisfaction and retention of rural midwives in Nigeria. Midwifery 31(10): 946-956. DOl: http://dx.doi.org/10.1016/j. midw.2015.06.010

Adeniyi, J.D., C.L. Ejembi, P. Igbineosun, D. Mohammed. 2001. The status of primary health care in Nigeria. Report of a needs assessment survey. National Primary Health Care Development Agency (NPHCDA) 2001: 1-100.

Adeniyi, J.O. and A. Soyibo. 2004. Study of primary healthcare delivery service in Nigeria: A quantitative survey approach, World Bank, Washington, DC.

Bagonza, et al. 2014. Performance of community health workers managing malaria, pneumonia and diarrhea under the community case management programme in central Uganda: A cross sectional Study. Malaria Journal 13: 367 www.malariajournal.com/content/13/1/367

Bloom, G., H. Standing, A. Joshi. 2009. Institutional Frameworks for Health Services in Low and Middle Income Countries, in Implementing Health Services Strategies in Low and Middle Income Countries: From Evidence to Learning and Doing. Eds. D.H. Peters, B. El Shirty, M. Siadat, M. Vujivic and K. Janovsky. Washington, DC: The World Bank. 2009.

Community Health Practitioners Registration Board of Nigeria. 2006. Curriculum for Certificate in Community Health; Junior Community Health Extension Worker

Community Health Worker Assessment and Improvement Matrix (CHW AIM). 2011. A Toolkit for Improving CHW Programs and Services by USAID 2011.

FMoH. 2014. Task-Shifting and Task-Sharing Policy for Maternal and New-born Health Care in Nigeria. February 2014.

Josephat Chinawa. 2015. Factors militating against effective implementation of primary health care (PHC) system in Nigeria.

Bluestone, J., P. Johnson, J. Fullerton, C. Carr, J. Alderman, J. BonTempo. 2013. Improving the efficiency, effectiveness and sustainability of health worker in-service training: Closing the gaps between evidence, practice and outcomes. Human Resources for Health 11: 51.

Midwifes Service Scheme (MSS) Series Making childbirth safer. 2012. A Quarterly Publication of the National Primary Health Care Development Agency 3.

Musa EO, Ejembi CL. 2004. Reasons and routine of paediatric referrals from first level health of facilities in Sabon Gari Zaria. Northwest Niger J Community Med Prim Health Care 16: 10-15.

National Population Commission (NPC) [Nigeria]; ICF International. Nigeria demographic and health survey 2013.Abuja (Nigeria): NPC; 2014. Co-published by ICF International.

National Population Commission (NPC) ICF Macro. Nigeria demographic and health survey 2008. Abuja, Nigeria: National Population Commission and ICF Macro; 2009.

National Population Commission, Federal Republic of Nigeria and ORC Macro. 2008. Nigeria Demographic and Health Survey 2008. Calverton, Maryland: National Population Commission and ORC Macro/USAID, April 2008. 
National Population Commission, Federal Republic of Nigeria and ORC Macro. 2014. Nigeria Demographic and Health Survey 2013. Calverton, Maryland: National Population Commission and ORC Macro/USAID, April 2013.

National Primary Health Care Development Agency (NPHCDA). 2015. Primary health care: Realities, challenges and the way forward.

National Primary Health Care Development Agency (NPHCDA). 2007. Minimum standards for Primary Health Care in Nigeria. Federal Republic of Nigeria, National Primary Health Care Development Agency. National guidelines for development of primary health care system in Nigeria. Fourth Revised Edition.

NDHS (National Population Commission [NPC]). 2008. Federal Republic of Nigeria and ORC Macro, 2014). (FMOH, 2013).

Nnebue, C.C., U.E. Ebenebe, P.O.U. Adogu, E.D. Adinma, C.O. Ifeadike, A.S. Nwabueze. 2014. Adequacy of resources for provision of maternal health services at the primary health care level in Nnewi, Nigeria. Niger Med J 55(3): 235-241. doi: 10.4103/0300-1652.132056

Emelumadu, O.F., U.U. Onyeonoro, A.U. Ukegbu, N.N. Ezeama, C.O. Ifeadike, O.K. Okezie. 2014. Perception of quality of maternal healthcare services among women utilising antenatal services in selected primary health facilities in Anambra State, Southeast Nigeria. Niger Med J. 55(2): 148-155. doi: 10.4103/0300-1652.129653

Oladepo, et al. 2014. Strengthening Patent Medicine Vendors' Associations in Nigeria for Improved Malaria Management (SPANIMM) Phase 1 Final Report. Future Health Systems Research Group. University of Ibadan, Nigeria and Niger Delta University, Nigeria.

Oladepo, O. 2015. Review of Curriculum for Community Health Officers (CHOs), Community Health Assistants (CHEW) and Junior Community Health Assistants (JCHEWs) Programmes, Nigeria. Save the Children, Nigeria.

Prata, N., G. Mbaruku, M. Campbell, M. Potts, F. Vahidnia. 2005. Controlling postpartum hemorrhage after home births in Tanzania. Int J. Gynecol Obstet 90(1): 51-55.

Schaider, J., S. Ngonyani, S. Tomlin, R. Rydman, R. Roberts. 1999. International maternal mortality reduction: outcome of traditional birth attendant education and intervention in Angola. J Med Syst 23(2): 99-105.

Seye, A., U. Okoli, O. Olubajo, M.J. Abdullahi, M.A. Pate. 2012. The midwives service scheme in Nigeria. PLoS Med. doi: 10.1371/journal.pmed.1001211. PMCID: PMC3341343

UNICEF/WHO/World Bank/UN Population Division Report. 2014. Level and Trend in Child Mortality, Report.

United Nations Children's Fund (UNICEF). Countdown to 2015: Tracking Progress in Maternal, Newborn and Child Survival. 2008. New York: UNICEF.

World Health Organization. 2010. Trends in Maternal Mortality: 1990-2008. Estimates developed by WHO, UNICEF, UNFPA and The World Bank. ISBN 9789241500265. 


\section{APPENDIX: Tables 3-18}

Table 3: Reported IIInesses of Women in the last 12 months

\begin{tabular}{|c|c|c|}
\hline & Bauchi, $n(\%)$ & Cross River, $n(\%)$ \\
\hline \multicolumn{3}{|l|}{ Illness Status } \\
\hline III & $399(65.09)$ & $405(66.7)$ \\
\hline Not III & $214(34.91)$ & $202(33.3)$ \\
\hline Total & $613(100)$ & $607(100)$ \\
\hline \multicolumn{3}{|l|}{ Nature of illness } \\
\hline None & 214 (34.91) & $202(33.3)$ \\
\hline Miscarriage & $12(1.96)$ & $4(0.66)$ \\
\hline Bleeding & $8(1.31)$ & $6(0.99)$ \\
\hline Shortage of Blood & $30(4.89)$ & $10(1.65)$ \\
\hline Convulsion in pregnancy & $32(5.22)$ & $1(0.16)$ \\
\hline Problem in labour & $20(3.26)$ & $5(0.8)$ \\
\hline Other Diseases & $297(48.45)$ & $379(62.44)$ \\
\hline \multicolumn{3}{|l|}{ Where Treated } \\
\hline Self-medication & $24(6.0)$ & $33(8.1)$ \\
\hline Chemist & $44(11.0)$ & $135(33.3)$ \\
\hline PMVs & $1(0.25)$ & $3(0.7)$ \\
\hline Traditional healer & $17(4.26)$ & $15(3.7)$ \\
\hline Spiritual homes & $0(0.0)$ & $2(0.5)$ \\
\hline Govt. hospital & $44(11.0)$ & $25(6.2)$ \\
\hline Comprehensive health centre & $90(22.6)$ & $14(3.5)$ \\
\hline PHC Centre & $165(41.4)$ & $115(28.4)$ \\
\hline Govt. health post & $11(2.76)$ & $31(7.7)$ \\
\hline Private clinic/hospital & $2(0.5)$ & $26(6.4)$ \\
\hline $\begin{array}{l}\text { Others (Mobile clinic, Role model/caregiver/community } \\
\text { worker, Pharmacy) }\end{array}$ & $1(0.25)$ & $6(1.5)$ \\
\hline Total & $399(100)$ & $405(100.0)$ \\
\hline \multicolumn{3}{|l|}{ Outcome of Treatment } \\
\hline Fully recovered & $233(58.4)$ & $236(58.3)$ \\
\hline Partially recovered & $148(37.1)$ & $100(24.7)$ \\
\hline Not yet recovered & $18(4.5)$ & $69(17.0)$ \\
\hline Total & $399(100)$ & $405(100)$ \\
\hline \multicolumn{3}{|l|}{ Level of Satisfaction } \\
\hline Highly satisfied & $140(35.1)$ & $122(30.1)$ \\
\hline Satisfied & $225(56.4)$ & $159(39.3)$ \\
\hline Not satisfied & $34(8.5)$ & $124(30.6)$ \\
\hline Total & 399 (100) & $405(100)$ \\
\hline
\end{tabular}


Table 4a: Reported IIInesses of Newborn in the last 12 months $(\mathrm{N}=657)$

\begin{tabular}{|c|c|c|}
\hline Variables & $\begin{array}{l}\text { Bauchi }(N=392) \\
n(\%)\end{array}$ & $\begin{array}{l}\text { Cross River }(N=265) \\
n(\%)\end{array}$ \\
\hline \multicolumn{3}{|l|}{ Status of illness } \\
\hline Not III & 155 (39.5) & $131(49.4)$ \\
\hline III & 237 (60.5) & $134(50.6)$ \\
\hline Total & $392(100)$ & $265(100)$ \\
\hline \multicolumn{3}{|l|}{ Illnesses experienced: Newborn } \\
\hline None & 155 (39.5) & $131(49.4)$ \\
\hline Baby with yellow eyes & $21(5.4)$ & $4(1.5)$ \\
\hline Breathing problem & $25(6.4)$ & $3(1.1)$ \\
\hline Watery stool & $143(36.5)$ & $29(10.9)$ \\
\hline Convulsion & $4(1.0)$ & $1(0.4)$ \\
\hline Baby not formed well from the womb & $0(0.0)$ & $2(0.8)$ \\
\hline Others specify (malaria, typhoid etc.) & $44(11.2)$ & 95 (35.9) \\
\hline Total & $392(100)$ & $265(100)$ \\
\hline \multicolumn{3}{|l|}{ Where treated } \\
\hline Self-medication & $14(3.6)$ & $18(6.8)$ \\
\hline PMVs & $25(6.4)$ & $32(12.1)$ \\
\hline Traditional healer & $7(1.8)$ & $8(3.0)$ \\
\hline Govt. hospital & 55 (14.0) & $5(1.9)$ \\
\hline Comprehensive health centre & $38(9.7)$ & $11(4.2)$ \\
\hline PHC Centre & $88(22.4)$ & $49(18.5)$ \\
\hline Govt. health post & $8(2.0)$ & $5(1.9)$ \\
\hline Private clinic/hospital & $1(0.3)$ & $3(1.1)$ \\
\hline Others (Caregiver/community worker, & $1(0.3)$ & $3(1.1)$ \\
\hline None & $155(39.5)$ & $131(49.4)$ \\
\hline Total & $392(100)$ & 265 (100) \\
\hline \multicolumn{3}{|l|}{ Outcome of treatment } \\
\hline Fully recovered & $117(29.8)$ & $88(33.2)$ \\
\hline Partially recovered & $111(28.3)$ & $36(13.6)$ \\
\hline Not yet recovered & $9(2.3)$ & $10(3.8)$ \\
\hline No treatment (not ill) & $155(39.5)$ & $131(49.4)$ \\
\hline Total & 392 (100) & 265 (100) \\
\hline \multicolumn{3}{|l|}{ Level of satisfaction } \\
\hline Highly satisfied & $55(14.0)$ & $54(20.4)$ \\
\hline Satisfied & $163(41.6)$ & $50(18.9)$ \\
\hline Not satisfied & $19(4.8)$ & $30(11.3)$ \\
\hline No treatment (not ill) & $155(39.5)$ & $131(49.4)$ \\
\hline Total & $392(100)$ & $265(100)$ \\
\hline
\end{tabular}

Source: Survey Data 
Table 4b: Reported Illnesses of Under-Five Children in the last 12 months

\begin{tabular}{|c|c|c|}
\hline Variables & Bauchi, $n=1555$ & Cross River, $n=891$ \\
\hline \multicolumn{3}{|l|}{ *IIInesses experienced } \\
\hline Fever & $865(55.6)$ & $444(49.8)$ \\
\hline Watery stool & $277(17.8)$ & $96(10.8)$ \\
\hline Cough with chest pain & $64(4.1)$ & $16(1.8)$ \\
\hline Skin rashes with fever & 185 (11.9) & $43(4.8)$ \\
\hline Cough with catarrh & $385(24.8)$ & $330(37.0)$ \\
\hline Pneumonia & $54(3.5)$ & $50(5.6)$ \\
\hline Malnutrition & $59(3.8)$ & $9(1.0)$ \\
\hline Others specify & $140(9.0)$ & $159(17.8)$ \\
\hline \multicolumn{3}{|l|}{ Where treated } \\
\hline Self-medication & $77(5.0)$ & $44(4.9)$ \\
\hline Chemist & $1(0.1)$ & $5(0.6)$ \\
\hline PMVs & $157(10.1)$ & $252(28.3)$ \\
\hline Traditional healer & $18(1.2)$ & $11(1.2)$ \\
\hline Government Hospital & $145(9.3)$ & $28(3.1)$ \\
\hline Comprehensive health centre & $213(13.7)$ & $29(3.3)$ \\
\hline PHC Centre & $458(29.5)$ & $208(23.3)$ \\
\hline Government health post & $74(4.8)$ & $73(8.2)$ \\
\hline $\begin{array}{l}\text { Caregiver/community worker } \\
\text { Pharmacy }\end{array}$ & $\begin{array}{l}3(0.2) \\
0(0.0)\end{array}$ & $\begin{array}{l}9(1.0) \\
8(0.3)\end{array}$ \\
\hline Private clinic/hospital & $3(0.2)$ & $19(2.1)$ \\
\hline No illness & $406(26.1)$ & $205(23.0)$ \\
\hline Total & $1555(100)$ & $891(100)$ \\
\hline \multicolumn{3}{|l|}{ Outcome of treatment } \\
\hline Fully recovered & $631(40.6)$ & $501(56.2)$ \\
\hline Partially recovered & $448(28.8)$ & $121(13.6)$ \\
\hline Not yet recovered & $70(4.5)$ & $64(7.2)$ \\
\hline No treatment & $406(26.1)$ & $205(23.0)$ \\
\hline Total & $1555(100)$ & $891(100)$ \\
\hline \multicolumn{3}{|l|}{ Level of satisfaction } \\
\hline Highly satisfied & $324(20.8)$ & $314(35.2)$ \\
\hline Satisfied & 706 (45.4) & $242(27.2)$ \\
\hline Not satisfied & $119(7.7)$ & $130(14.6)$ \\
\hline No treatment & $406(26.1)$ & $205(23.0)$ \\
\hline Total & 1555 (100) & $891(100)$ \\
\hline
\end{tabular}

*Multiple responses.

Source - Survey Data 
Table 5a: Reported Causes of Death for Women and Under-Five Children in the Six Months prior to data collection

\begin{tabular}{|c|c|c|}
\hline & Bauchi, $n=34$ & Cross River, $n=30$ \\
\hline Women & $\mathrm{n}(\%)$ & n (\%) \\
\hline \multicolumn{3}{|l|}{ *Causes of death } \\
\hline Shortage of blood & $4(11.8)$ & $0(0.0)$ \\
\hline Convulsion during pregnancy & $2(5.9)$ & $0(0.0)$ \\
\hline Bleeding & $1(2.9)$ & $1(3.3)$ \\
\hline Problem during pregnancy & $6(17.7)$ & $4(13.3)$ \\
\hline Problem during labour & $8(23.5)$ & $3(10.0)$ \\
\hline God wishes & $13(38.2)$ & $11(36.7)$ \\
\hline Other diseases & $10(29.4)$ & $14(46.7)$ \\
\hline \multicolumn{3}{|l|}{ Reasons for the deaths } \\
\hline Inadequate attention and care by health workers & $14(41.2)$ & $6(20.0)$ \\
\hline Inadequate food intake during pregnancy & $5(14.7)$ & $1(3.3)$ \\
\hline $\begin{array}{l}\text { Spiritual attack } \\
\text { Lack of money }\end{array}$ & $\begin{array}{c}12(35.3) \\
1(2.9)\end{array}$ & $\begin{aligned} 22 & (73.3) \\
1 & (3.3)\end{aligned}$ \\
\hline Far distance to health facilities & $1(2.9)$ & $0(0.0)$ \\
\hline Others/Don't know & $1(2.9)$ & $0(0.0)$ \\
\hline Under-five & $\mathrm{N}=90$ & $\mathrm{~N}=21$ \\
\hline \multicolumn{3}{|l|}{ *Causes of death } \\
\hline Fever & $58(64.4)$ & $11(52.4)$ \\
\hline Watery stool & $16(17.8)$ & $4(19.0)$ \\
\hline Cough with pain in chest & $11(12.2)$ & $2(9.5)$ \\
\hline Measles & $15(16.7)$ & $0(0.0)$ \\
\hline Cough with catarrh & $7(7.8)$ & $0(0.0)$ \\
\hline Malnutrition & $7(7.8)$ & $1(4.8)$ \\
\hline Accident & $5(5.6)$ & $3(14.3)$ \\
\hline God wishes & $77(85.6)$ & $7(33.3)$ \\
\hline \multicolumn{3}{|l|}{ Reasons for death } \\
\hline Lack of adequate care & $6(6.7)$ & $6(28.6)$ \\
\hline Lack of qualified personnel & $7(7.8)$ & $2(9.5)$ \\
\hline Lack of money & $17(18.9)$ & $1(4.8)$ \\
\hline Far distance to health facilities & $8(8.9)$ & $5(23.8)$ \\
\hline Others/Don't know & $52(57.8)$ & 7 (33.3) \\
\hline
\end{tabular}

*Multiple responses

Source - Survey Data 
Table 5b: Reported Causes of Death for Newborns in the six Months prior to data collection Bauchi, $n=53$

Cross River, $n=26$

*Causes of newborn death

Baby with yellow eyes

$0(0.0)$

1 (3.8)

Baby born before 9 months

2 (3.8)

$0(0.0)$

Breathing problem

5 (9.4)

5 (19.2)

Watery stool

2 (3.8)

4 (15.4)

Diseases

4 (7.5)

$6(23.1)$

Baby not formed well from the womb

$1(1.9)$

$2(7.7)$

Sudden death of baby

$13(24.5)$

4 (15.4)

Unknown causes

22 (41.5)

Nose blocking

$0(0.0)$

$8(30.8)$

Blocking of throat during feeding

$1(1.9)$

$0(0.0)$

Infections

$1(1.9)$

$0(0.0)$

Others specify

$11(20.8)$

$3(11.5)$

Reasons for death

Lack of adequate care

1 (1.9)

8 (30.8)

Lack of qualified personnel

$0(0.0)$

7 (26.9)

Lack of money

4 (7.5)

4 (15.4)

God wishes

$47(88.7)$

4 (15.4)

Far distance to health facilities

1 (1.9)

$10(38.5)$

4 (15.4)

*Multiple Responses

Source - Survey Data 
Table 6: FLHWs Socio Demographic Information by Cadre and State.

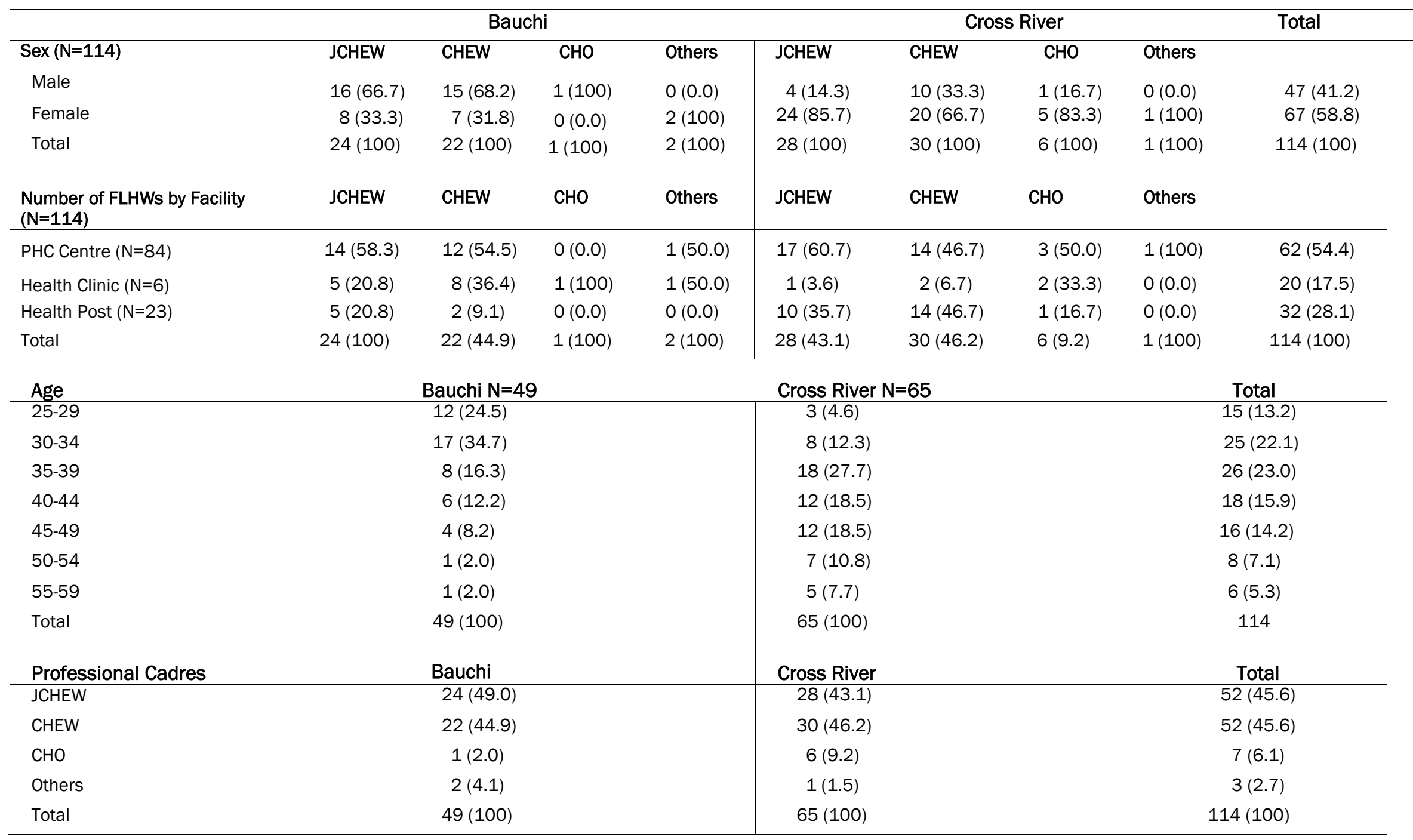

Source - Survey Data 
Table 7: FLHWs' Knowledge of Expected Roles in PHC (*N=110)

\begin{tabular}{|c|c|c|c|c|c|c|c|c|c|}
\hline \multirow[b]{2}{*}{$\begin{array}{l}\text { Good Knowledge } \\
\text { of } \\
\text { Roles }(* N=110)\end{array}$} & \multicolumn{4}{|c|}{ Bauchi } & \multicolumn{4}{|c|}{ Cross River } & \multirow[b]{2}{*}{ Total } \\
\hline & JCHEW & CHEW & $\mathrm{CHO}$ & Others & JCHEW & CHEW & $\mathrm{CHO}$ & Others & \\
\hline $\begin{array}{l}\text { Planning and } \\
\text { organising maternal }\end{array}$ & $12(522)$ & $15(714)$ & $0(0,0)$ & $1(1000)$ & $16(571)$ & $27(900)$ & $6(1000)$ & $0(0,0)$ & $77(700)$ \\
\hline $\begin{array}{l}\text { and child health } \\
\text { programmes } \\
\text { Health education } \\
\text { and counselling }\end{array}$ & 21 (91.3) & $21(100.0)$ & $1(100.0)$ & $1(100.0)$ & $27(94.4)$ & $29(96.7)$ & $6(100.0)$ & $0(0.0)$ & $106(96.3)$ \\
\hline $\begin{array}{l}\text { Community } \\
\text { mobilisation }\end{array}$ & $22(95.7)$ & $21(100.0)$ & $1(100.0)$ & $1(100.0)$ & 27 (96.4) & $30(100.0)$ & $6(100.0)$ & $0(0.0)$ & $108(98.2)$ \\
\hline $\begin{array}{l}\text { Provide integrated } \\
\text { PHC services }\end{array}$ & $16(69.6)$ & $20(95.2)$ & $1(100.0)$ & $1(100.0)$ & $20(71.4)$ & $29(96.7)$ & $6(100.0)$ & $0(0.0)$ & $93(84.5)$ \\
\hline $\begin{array}{l}\text { Provision of } \\
\text { antenatal care services }\end{array}$ & $14(60.9)$ & $20(95.2)$ & $0(0.0)$ & $1(100.0)$ & 26 (92.9) & $29(96.7)$ & 5 (83.3) & $0(0.0)$ & 95 (86.4) \\
\hline $\begin{array}{l}\text { Conduct of } \\
\text { delivery }\end{array}$ & $11(47.8)$ & $19(90.5)$ & $0(0.0)$ & $1(100.0)$ & $22(78.6)$ & $30(100.0)$ & $6(100.0)$ & $0(0.0)$ & 89 (80.9) \\
\hline $\begin{array}{l}\text { Provision of post- } \\
\text { natal services }\end{array}$ & $11(47.8)$ & $19(90.5)$ & $0(0.0)$ & 1 (100.0) & $22(78.6)$ & $30(100.0)$ & $6(100.0)$ & $0(0.0)$ & 89 (80.9) \\
\hline $\begin{array}{l}\text { Treatment of } \\
\text { minor ailments }\end{array}$ & $23(100.0)$ & $21(100.0)$ & $1(100.0)$ & $1(100.0)$ & $27(96.4)$ & $30(100.0)$ & $6(100.0)$ & $0(0.0)$ & 109 (99.1) \\
\hline $\begin{array}{l}\text { Provision of child } \\
\text { health services }\end{array}$ & $19(82.6)$ & 21 (100.0) & $1(100.0)$ & $1(100.0)$ & $28(100.0)$ & $29(96.7)$ & $6(100.0)$ & $0(0.0)$ & 105 \\
\hline Home visits & $20(87.0)$ & $21(100.0)$ & $1(100.0)$ & $1(100.0)$ & $27(96.4)$ & $29(96.7)$ & $5(83.3)$ & $0(0.0)$ & $104(94.5)$ \\
\hline $\begin{array}{l}\text { Simple laboratory } \\
\text { test }\end{array}$ & $10(53.5)$ & $18(85.7)$ & $1(100.0)$ & $1(100.0)$ & $20(71.4)$ & $22(73.3)$ & $5(83.3)$ & $0(0.0)$ & $77(70.0)$ \\
\hline $\begin{array}{l}\text { Record keeping } \\
\text { and documentation }\end{array}$ & $18(78.3)$ & $20(95.2)$ & $1(100.0)$ & $1(100.0)$ & $26(100.0)$ & $30(100.0)$ & 5 (100.0) & $0(0.0)$ & 101 (91.8) \\
\hline $\begin{array}{l}\text { Training of other } \\
\text { community health } \\
\text { workers }\end{array}$ & $13(56.5)$ & $16(76.2)$ & $1(100.0)$ & $1(100.0)$ & $11(39.3)$ & $24(80.0)$ & 5 (83.3) & $0(0.0)$ & $71(64.5)$ \\
\hline
\end{tabular}

Source -Survey Data

*110 frontline health workers responded to the knowledge questions; total column represents ' $n$ (\%) of good knowledge of role responses' out of 110 . 
Table 8: FLHWs Knowledge of Essential MNCH Issues ( $N=110)$

\begin{tabular}{|c|c|c|c|c|c|c|c|c|c|c|c|}
\hline & & & Bauchi & & & & & Cross Rive & & & \\
\hline & $\begin{array}{l}\text { JCHEW } \\
(\mathrm{N}=23)\end{array}$ & $\begin{array}{l}\text { CHEW } \\
(\mathrm{N}=21)\end{array}$ & $\begin{array}{l}{ }^{*} \mathrm{CHO} \\
(\mathrm{N}=1)\end{array}$ & $\begin{array}{l}\text { Others } \\
(\mathrm{N}=1)\end{array}$ & $\begin{array}{l}\text { Total } \\
(\mathrm{N}=46)\end{array}$ & $\begin{array}{l}\text { JCHEW } \\
(\mathrm{N}=28)\end{array}$ & $\begin{array}{l}\text { CHEW } \\
(\mathrm{N}=30)\end{array}$ & $\begin{array}{l}{ }^{*} \mathrm{CHO} \\
(\mathrm{N}=6)\end{array}$ & $\begin{array}{l}\text { Others } \\
(\mathrm{N}=0)\end{array}$ & $\begin{array}{l}\text { Total } \\
(\mathrm{N}=64)\end{array}$ & $\begin{array}{l}\text { Grand Total } \\
(\mathrm{N}=110)\end{array}$ \\
\hline Poor (7 marks or less) & $8(34.8)$ & $1(4.8)$ & $0(0.0)$ & $0(0.0)$ & $9(19.6)$ & $2(7.1)$ & $0(0.0)$ & $0(0.0)$ & $0(0.0)$ & $2(3.1)$ & $11(10.0)$ \\
\hline Good (8-10 marks) & $7(30.4)$ & $2(9.5)$ & $1(100)$ & $0(0.0)$ & $10(21.7)$ & $8(26.8)$ & $3(10.0)$ & $1(16.7)$ & $0(0.0)$ & $12(18.8)$ & $22(20.0)$ \\
\hline Excellent (11marks above) & $8(34.8)$ & $18(85.7)$ & $0(0.0)$ & $1(100)$ & $27(58.7)$ & $18(64.3)$ & 27 (90.0) & $5(83.3)$ & $0(0.0)$ & $50(78.1)$ & 77 (70.0) \\
\hline
\end{tabular}

Source: Survey Data 
Table 9: Average number of clients seen in a day by different cadres of FLHWs (to nearest whole numbers)

\begin{tabular}{lcc}
\hline & Bauchi & Cross River \\
\hline CHOs & 20 & 3 \\
CHEWs & 21 & 7 \\
JCHEWs & 16 & 5 \\
Others & 25 & 5 \\
& & \\
\hline \multicolumn{1}{c}{ Source: Survey Data } & &
\end{tabular}

Table 10: Client Referral by FLHWs (Total for Both States) $\mathrm{N}=114$

\begin{tabular}{|c|c|c|c|c|c|}
\hline & JCHEW & CHEW & $\mathrm{CHO}$ & Others & Total \\
\hline $\begin{array}{l}\text { Referred clients for health } \\
\text { services you do not or cannot provide }\end{array}$ & $46(90.2)$ & 45 (84.9) & $6(85.7)$ & 3 (100) & $100(87.7)$ \\
\hline $\begin{array}{l}\text { Complete a referral form for the } \\
\text { client to take to the facility }\end{array}$ & $45(88.2)$ & $42(79.2)$ & $6(85.7)$ & $2(66.7)$ & 95 (83.3) \\
\hline \multirow[t]{2}{*}{$\begin{array}{l}\text { Received any feedback from the } \\
\text { facility that you referred clients }\end{array}$} & 27 (52.9) & $35(66)$ & 3 (42.9) & $2(66.7)$ & 67 (58.8) \\
\hline & PHC & $\begin{array}{l}\text { Health } \\
\text { Clinic }\end{array}$ & $\begin{array}{l}\text { Health } \\
\text { Post }\end{array}$ & & Total \\
\hline $\begin{array}{l}\text { Referring clients for health } \\
\text { services you do not or cannot provide }\end{array}$ & $53(96.4)$ & $18(94.7)$ & 29 (90.6) & & $100(87.7)$ \\
\hline $\begin{array}{l}\text { Complete a referral form for the } \\
\text { client to take to the facility }\end{array}$ & 57 (91.9) & $16(80.0)$ & $22(68.8)$ & & 95 (83.3) \\
\hline
\end{tabular}

Source: Survey Data 
Table 11: Client referral by FLHWs (Disaggregated by States)

\begin{tabular}{|c|c|c|c|c|c|c|c|c|c|}
\hline \multirow[b]{2}{*}{ Type of FLHWs } & \multicolumn{4}{|c|}{ Bauchi } & \multicolumn{5}{|c|}{ Cross River } \\
\hline & JCHEW & CHEW & $\mathrm{CHO}$ & Others & JCHEW & CHEW & $\mathrm{CHO}$ & Others & $\begin{array}{l}\text { Total } \\
(\mathrm{N}=114)\end{array}$ \\
\hline Referred clients for health services & $20(83.3)$ & $18(81.8)$ & - & $2(100)$ & $26(92.8)$ & $27(90.0)$ & $6(100)$ & $1(100)$ & $100(87.7)$ \\
\hline $\begin{array}{l}\text { Completed a referral form for the } \\
\text { client to take to next facility }\end{array}$ & $19(79.2)$ & $17(77.3)$ & $1(100)$ & $1(50.0)$ & $26(92.9)$ & $25(83.3)$ & $5(83.3)$ & $1(100)$ & 95 (83.3) \\
\hline $\begin{array}{l}\text { Received feedback from the referred } \\
\text { facility }\end{array}$ & $11(45.8)$ & $11(50.0)$ & - & $1(50.0)$ & $16(57.1)$ & $24(80.0)$ & $3(50.0)$ & $1(100)$ & $67(58.8)$ \\
\hline \multicolumn{2}{|l|}{ Facility type } & $\mathrm{PHC}$ & $\begin{array}{l}\text { Health } \\
\text { Clinic }\end{array}$ & Health Post & \multicolumn{2}{|c|}{ PHC } & $\begin{array}{l}\text { Health } \\
\text { Clinic }\end{array}$ & $\begin{array}{l}\text { Health } \\
\text { Post }\end{array}$ & Total \\
\hline \multicolumn{2}{|l|}{ Referred clients for health services } & $20(90.9)$ & $13(92.9)$ & $7(100.0)$ & \multicolumn{2}{|c|}{$33(100.0)$} & $5(100.0)$ & $22(88.0)$ & $100(87.7)$ \\
\hline \multicolumn{2}{|c|}{$\begin{array}{l}\text { Completed a referral form for the client to take to } \\
\text { next facility }\end{array}$} & $23(85.2)$ & $12(80.0)$ & $3(42.9)$ & & & $4(80.0)$ & $19(76.0)$ & 95 (83.3) \\
\hline \multicolumn{2}{|c|}{$\begin{array}{l}\text { Received feedback from the referred facility } \\
(N=114)\end{array}$} & $12(44.4)$ & $6(40.0)$ & $5(71.4)$ & & & $4(80.0)$ & $16(64.0)$ & $67(58.8)$ \\
\hline
\end{tabular}


Table 12: Number of Households visited in the past 6 months by FLHWs

\begin{tabular}{|c|c|c|c|c|c|c|c|c|c|c|c|}
\hline \multirow[b]{2}{*}{$\begin{array}{l}\text { No of } H H \\
\text { visited }\end{array}$} & \multicolumn{5}{|c|}{ Bauchi } & \multicolumn{5}{|c|}{ Cross River } & \multirow[t]{2}{*}{$\begin{array}{l}\text { Overall Total } \\
(\mathrm{N}=114)\end{array}$} \\
\hline & $\begin{array}{l}\text { JCHEW } \\
(\mathrm{N}=24)\end{array}$ & $\begin{array}{l}\text { CHEW } \\
(\mathrm{N}=22)\end{array}$ & $\begin{array}{l}\mathrm{CHO} \\
(\mathrm{N}=1)\end{array}$ & $\begin{array}{l}\text { Others } \\
(\mathrm{N}=2)\end{array}$ & $\begin{array}{l}\text { Total } \\
(\mathrm{N}=49)\end{array}$ & $\begin{array}{l}\text { JCHEW } \\
(\mathrm{N}=28)\end{array}$ & $\begin{array}{l}\text { CHEW } \\
(\mathrm{N}=30)\end{array}$ & $\begin{array}{l}\mathrm{CHO} \\
(\mathrm{N}=6)\end{array}$ & $\begin{array}{l}\text { Others } \\
(\mathrm{N}=1)\end{array}$ & Total $(\mathrm{N}=65)$ & \\
\hline $1-20$ & $21(87.5)$ & $18(81.8)$ & $1(100)$ & $1(50.0)$ & $41(83.7)$ & $22(78.6)$ & $23(76.7)$ & $6(100)$ & - & $52(80.0)$ & 93 (81.6) \\
\hline $21-40$ & $3(12.5)$ & 4 (18.2) & $0(0.0)$ & $1(50.0)$ & $8(16.3)$ & 5 (17.9) & $6(20.0)$ & $0(0.0)$ & - & $11(16.9)$ & 19 (16.7) \\
\hline$>40$ & - & - & - & - & - & $1(3.6)$ & $1(3.3)$ & $0(0.0)$ & - & $2(3.1)$ & $2(1.8)$ \\
\hline
\end{tabular}

Table 13: Support received by different cadres of frontline health workers from village/ward development committees

\begin{tabular}{|c|c|c|c|c|c|c|c|}
\hline & JCHEW & CHEW & $\mathrm{CHO}$ & Nurse & Midwife & Volunteer & Total \\
\hline Shared Medicines & $31(62.0)$ & $15(30.0)$ & $4(8.0)$ & $0(0.0)$ & $0(0.0)$ & $0(0.0)$ & 50 \\
\hline Referred Patients to facility & $35(47.9)$ & $32(43.8)$ & $4(5.5)$ & $1(1.4)$ & $1(1.4)$ & $0(0.0)$ & 73 \\
\hline $\begin{array}{l}\text { Sharing Knowledge about MNCH } \\
\text { Prevention/Treatment }\end{array}$ & $43(46.2)$ & 41 (44.1) & $6(6.5)$ & $1(1.1)$ & $2(2.2)$ & $3(100)$ & 93 \\
\hline $\begin{array}{l}\text { Community Mobilization to use health } \\
\text { services }\end{array}$ & $43(45.3)$ & $44(46.3)$ & $5(5.3)$ & $1(1.1)$ & $2(2.1)$ & $0(0.0)$ & 95 \\
\hline Help with record keeping & $34(42.5)$ & $39(48.8)$ & $4(5.0)$ & $1(1.2)$ & $2(2.5)$ & $0(0.0)$ & 80 \\
\hline Appreciation/Recognition & $39(46.4)$ & $41(48.8)$ & $3(3.6)$ & $0(0.0)$ & $1(1.2)$ & $0(0.0)$ & 84 \\
\hline No Support & $2(66.7)$ & $1(33.3)$ & $0(0.0)$ & $0(0.0)$ & $0(0.0)$ & $0(0.0)$ & 3 \\
\hline Salary or Stipend & $32(52.5)$ & $24(39.3)$ & $4(6.6)$ & $1(1.6)$ & $0(0.0)$ & $0(0.0)$ & 61 \\
\hline Other In-Kind of Payment & $11(73.3)$ & $3(20.0)$ & $1(6.7)$ & $0(0.0)$ & $0(0.0)$ & $0(0.0)$ & 15 \\
\hline
\end{tabular}


Table 14: Staff experience with Stock-Out (Equipment/Supply) [Bauchi]

\begin{tabular}{|c|c|c|c|c|c|c|c|c|c|c|c|c|}
\hline & \multicolumn{3}{|c|}{$\begin{array}{ll}\text { JCHEW } & \mathrm{N}=24\end{array}$} & \multicolumn{3}{|c|}{ CHEW $\quad \mathrm{N}=22$} & \multicolumn{3}{|c|}{$\mathrm{CHO} \quad \mathrm{N}=1$} & \multicolumn{3}{|c|}{ Others $\quad \mathrm{N}=2$} \\
\hline & Always & Some & Never & Always & Some & Never & Always & Some & Never & Always & Some & Never \\
\hline Fetoscope & $10(41.7)$ & $8(33.3)$ & $6(25.0)$ & $5(22.7)$ & $6(27.3)$ & $11(50.0)$ & $0(0.0)$ & $0(0.0)$ & $1(100)$ & $1(50.0)$ & $0(0.0)$ & $1(50.0)$ \\
\hline Delivery Kits & $8(33.3)$ & $9(37.5)$ & $7(29.2)$ & $5(22.7)$ & $10(45.5)$ & $7(31.8)$ & $0(0.0)$ & $0(0.0)$ & $1(100)$ & $1(50.0)$ & $1(50.0)$ & $0(0.0)$ \\
\hline Delivery couch & $7(29.2)$ & $9(37.5)$ & $8(33.4)$ & 9 (40.9) & $8(36.4)$ & $5(22.7)$ & $0(0.0)$ & $0(0.0)$ & $1(100)$ & $1(50.0)$ & $0(0.0)$ & $1(50.0)$ \\
\hline Thermometer & $6(25.0)$ & $6(25.0)$ & $12(50.0)$ & 9 (40.9) & $4(18.2)$ & $9(40.9)$ & $0(0.0)$ & $0(0.0)$ & $1(100)$ & $1(50.0)$ & $0(0.0)$ & $1(50.0)$ \\
\hline $\begin{array}{l}\text { Blood measuring } \\
\text { apparatus }\end{array}$ & $5(20.8)$ & 7 (29.2) & $12(50.0)$ & $8(36.4)$ & $5(22.7)$ & $9(40.9)$ & $0(0.0)$ & $0(0.0)$ & $1(100)$ & $1(50.0)$ & $1(50.0)$ & $0(0.0)$ \\
\hline Misoprostol & $9(37.5)$ & $9(37.5)$ & $6(25.0)$ & $8(36.4)$ & 9 (40.9) & $5(22.7)$ & $0(0.0)$ & $0(0.0)$ & $1(100)$ & $1(50.0)$ & $1(50.0)$ & $0(0.0)$ \\
\hline Weighing scale & $6(25.0)$ & $4(16.7)$ & $14(58.3)$ & $4(18.2)$ & 9 (40.9) & 9 (40.9) & $0(0.0)$ & $0(0.0)$ & $1(100)$ & $0(0.0)$ & $1(50.0)$ & $1(50.0)$ \\
\hline Stethoscope & $6(25.0)$ & $6(25.0)$ & $12(50.0)$ & $8(36.4)$ & $7(31.8)$ & $7(31.8)$ & $0(0.0)$ & $0(0.0)$ & $1(100)$ & $1(50.0)$ & $1(50.0)$ & $0(0.0)$ \\
\hline $\begin{array}{l}\text { Table and stool for } \\
\text { gynaecological } \\
\text { examination }\end{array}$ & $10(41.7)$ & $6(25.0)$ & $8(33.3)$ & $9(40.9)$ & $6(27.3)$ & $7(31.8)$ & $0(0.0)$ & $0(0.0)$ & $1(100)$ & $1(50.0)$ & $0(0.0)$ & $1(50.0)$ \\
\hline Forceps & $7(70.0)$ & 9 (42.9) & $8(44.4)$ & $3(30.0)$ & $11(52.4)$ & $8(44.4)$ & $0(0.0)$ & $0(0.0)$ & $1(5.6)$ & $0(0.0)$ & $1(4.8)$ & $1(5.6)$ \\
\hline $\begin{array}{l}\text { Urinometer and urine test } \\
\text { kit }\end{array}$ & $9(37.5)$ & 8 (33.3) & $7(29.2)$ & $8(36.4)$ & $8(36.4)$ & $6(27.3)$ & $0(0.0)$ & $0(0.0)$ & $1(100)$ & $1(50.0)$ & $0(0.0)$ & $1(50.0)$ \\
\hline $\begin{array}{l}\text { Cool box for carrying } \\
\text { vaccines/pack }\end{array}$ & $8(33.3)$ & $5(20.8)$ & 11(45.8) & $8(36.4)$ & $7(31.8)$ & $7(31.8)$ & $0(0.0)$ & $0(0.0)$ & $1(100)$ & $1(50.0)$ & $1(50.0)$ & $0(0.0)$ \\
\hline Generator & 15 (62.5) & $3(12.5)$ & $6(25.0)$ & $9(40.9)$ & $4(18.2)$ & $9(40.9)$ & $0(0.0)$ & $0(0.0)$ & $1(100)$ & $1(50.0)$ & $1(50.0)$ & $0(00.0)$ \\
\hline Electricity & $12(50.0)$ & $8(33.3)$ & $4(16.7)$ & $6(27.3)$ & $11(50.0)$ & $5(22.7)$ & $0(0.0)$ & $1(100)$ & $0(0.0)$ & $1(50.0)$ & $0(0.0)$ & $1(50.0)$ \\
\hline Water supply & $12(50.0)$ & $5(20.8)$ & $7(29.2)$ & $8(36.4)$ & $6(27.3)$ & $8(36.4)$ & $0(0.0)$ & $1(100)$ & $0(0.0)$ & $1(50.0)$ & $1(50.0)$ & $0(0.0)$ \\
\hline
\end{tabular}

Source: Survey data 
Table 15: Staff experience with Stock-Out (Equipment/Supply) [Cross River]

\begin{tabular}{|c|c|c|c|c|c|c|c|c|c|c|c|c|}
\hline & \multirow{2}{*}{$\begin{array}{l}\text { JCHEW } \\
\text { Always }\end{array}$} & \multicolumn{2}{|c|}{$\mathrm{N}=25$} & \multirow{2}{*}{$\begin{array}{l}\text { CHEW } \\
\text { Always }\end{array}$} & \multicolumn{2}{|c|}{$\mathrm{N}=30$} & \multicolumn{2}{|c|}{$\mathrm{CHO}$} & \multirow{2}{*}{$\begin{array}{l}\mathrm{N}=6 \\
\text { Never }\end{array}$} & \multirow[b]{2}{*}{ Always } & Others & \multirow{2}{*}{$\begin{array}{l}\mathrm{N}=4 \\
\text { Never }\end{array}$} \\
\hline & & Some & Never & & Some & Never & Always & Some & & & Some & \\
\hline Fetoscope & $6(24.0)$ & $8(32.0)$ & $11(44.0)$ & $9(30.0)$ & 7 (23.3) & $14(46.7)$ & 2 (33.3) & $1(16.7)$ & $3(50.0)$ & $2(50.0)$ & $0(0.0)$ & $2(50.0)$ \\
\hline Delivery Kits & $10(40.0)$ & $10(40.0)$ & $5(20.0)$ & 13 (43.3) & $8(26.7)$ & $9(30.0)$ & $3(50.0)$ & $1(16.7)$ & $2(33.3)$ & $1(25.0)$ & $2(50.0)$ & $1(25.0)$ \\
\hline Delivery couch & 8 (32.0) & $6(24.0)$ & $11(44.0)$ & $13(43.3)$ & $3(10.0)$ & $14(46.7)$ & $1(16.7)$ & $1(16.7)$ & $4(66.7)$ & $2(50.0)$ & $\mathrm{O}(0.0)$ & $2(50.0)$ \\
\hline Thermometer & $13(52.0)$ & $7(28.0)$ & $5(20.0)$ & $10(33.3)$ & 7 (23.3) & $13(43.3)$ & $3(50.0)$ & 2 (33.3) & $1(16.7)$ & $2(50.0)$ & $1(25.0)$ & $1(25.0)$ \\
\hline $\begin{array}{l}\text { Blood measuring } \\
\text { apparatus }\end{array}$ & $11(44.0)$ & $8(32.0)$ & $6(24.0)$ & $18(60.0)$ & $6(20.0)$ & $6(20.0)$ & $5(83.3)$ & $1(16.7)$ & $0(0.0)$ & $2(50.0)$ & $2(50.0)$ & $0(0.0)$ \\
\hline Misoprostol & 13 (52.0) & $4(16.0)$ & $8(32.0)$ & $14(46.7)$ & 7 (23.3) & $9(30.0)$ & $4(66.7)$ & $1(16.7)$ & $1(16.7)$ & $3(75.0)$ & $0(0.0)$ & $1(25.0)$ \\
\hline Weighing scale & 11 (44.0) & $5(20.0)$ & $9(36.0)$ & $10(33.3)$ & $3(10.0)$ & $17(56.7)$ & $2(33.3)$ & $1(16.7)$ & $3(50.0)$ & $1(25.0)$ & $0(0.0)$ & $3(75.0)$ \\
\hline Stethoscope & $10(40.0)$ & $7(28.0)$ & $8(32.0)$ & $14(46.7)$ & 4 (13.3) & $12(40.0)$ & $1(16.7)$ & 2 (33.3) & $3(50.0)$ & $2(50.0)$ & $1(25.0)$ & $1(25.0)$ \\
\hline $\begin{array}{l}\text { Table and stool for } \\
\text { gynaecological } \\
\text { examination }\end{array}$ & 12 (48.0) & $4(16.0)$ & 9 (36.0) & $15(50.0)$ & $4(13.3)$ & $11(36.7)$ & $4(66.7)$ & $0(0.0)$ & $2(33.3)$ & $1(25.0)$ & $1(25.0)$ & $2(50.0)$ \\
\hline Forceps & 7 (28.0) & $11(44.0)$ & 7 (28.0) & $14(46.7)$ & 4 (13.3) & $12(40.0)$ & $1(16.7)$ & 2 (33.3) & $3(50.0)$ & $1(25.0)$ & $0(0.0)$ & $3(75.0)$ \\
\hline $\begin{array}{l}\text { Urinometer and urine } \\
\text { test kit }\end{array}$ & $15(60.0)$ & $8(32.0)$ & $2(8.0)$ & $22(73.3)$ & $1(3.3)$ & 7 (23.3) & $4(66.7)$ & $1(16.7)$ & $1(16.7)$ & $1(25.0)$ & $1(25.0)$ & $2(50.0)$ \\
\hline $\begin{array}{l}\text { Cool box for carrying } \\
\text { vaccines/pack }\end{array}$ & $7(28.0)$ & $8(32.0)$ & $10(40.0)$ & $17(56.7)$ & 4 (13.3) & $9(30.0)$ & 2 (33.3) & $1(16.7)$ & $3(50.0)$ & $1(25.0)$ & $0(0.0)$ & $3(75.0)$ \\
\hline Generator & $14(56.0)$ & $4(16.0)$ & 7 (28.0) & $16(53.3)$ & $5(16.7)$ & $9(30.0)$ & $2(33.3)$ & $1(16.7)$ & $3(50.0)$ & $0(0.0)$ & $3(75.0)$ & $1(25.0)$ \\
\hline Electricity & $12(48.0)$ & $6(24.0)$ & 7 (28.0) & $18(60.0)$ & $6(20.0)$ & $6(20.0)$ & $4(66.7)$ & $1(16.7)$ & $1(16.7)$ & $1(25.0)$ & $2(50.0)$ & $1(25.0)$ \\
\hline Water supply & $13(52.0)$ & $5(20.0)$ & 7 (28.0) & $18(60.0)$ & $2(6.7)$ & $10(33.3)$ & $4(66.7)$ & $0(0.0)$ & $2(33.3)$ & $2(50.0)$ & $0(0.0)$ & $2(50.0)$ \\
\hline
\end{tabular}

Source: Survey Data 
Table 16: Health facilities' readiness to see clients by States

\begin{tabular}{|c|c|c|}
\hline Variable & $\begin{array}{l}\text { Bauchi } \\
N=26\end{array}$ & $\begin{array}{c}\text { Cross River } \\
N=40\end{array}$ \\
\hline \multicolumn{3}{|l|}{ Level of facility cleanliness } \\
\hline Very Dirty & $4(15.4)$ & $3(7.5)$ \\
\hline Dirty & $5(19.2)$ & $5(12.5)$ \\
\hline Clean & $15(57.7)$ & $28(70.0)$ \\
\hline Very Clean & $2(7.7)$ & $4(10.0)$ \\
\hline Total & $26(100)$ & $40(100)$ \\
\hline \multicolumn{3}{|l|}{ Structural defects } \\
\hline Leaking roof & $20(76.9)$ & $18(45.0)$ \\
\hline Broken down doors and windows & $15(57.7)$ & $17(42.5)$ \\
\hline Cracked floor & $15(57.7)$ & $20(50.0)$ \\
\hline Provision for washing hands & $13(50.0)$ & $27(67.5)$ \\
\hline Functioning toilet & $14(53.8)$ & $19(47.5)$ \\
\hline \multicolumn{3}{|l|}{ Sterilization of medical equipment } \\
\hline Autoclave & $1(3.8)$ & $0(0.0)$ \\
\hline Dry heat sterilization & $2(7.7)$ & $0(0.0)$ \\
\hline Steam sterilization & $7(26.9)$ & $8(20.0)$ \\
\hline Boiling & $14(53.9)$ & $25(62.5)$ \\
\hline Others & $2(7.7)$ & $7(17.5)$ \\
\hline Total & $26(100)$ & $40(100)$ \\
\hline \multicolumn{3}{|l|}{ Others } \\
\hline No sterilization is done, rather she uses jik & $0(0.0)$ & $1(2.5)$ \\
\hline Born and buried & $1(3.8)$ & $0(0.0)$ \\
\hline Disposed & $1(3.8)$ & $0(0.0)$ \\
\hline None & $0(0.0)$ & $1(2.5)$ \\
\hline Soak in jik & $0(0.0)$ & $1(2.5)$ \\
\hline Sterilize with spirit and dried in sun & $0(0.0)$ & $1(2.5)$ \\
\hline Use already sterilized item from packs & $0(0.0)$ & $1(2.5)$ \\
\hline Use of JIK & $0(0.0)$ & $2(5.0)$ \\
\hline \multicolumn{3}{|l|}{ Storage of vaccines in the facility } \\
\hline Electric fridge/freezer for vaccines & $7(26.9)$ & $10(25.0)$ \\
\hline Electric fridge/freezer for vaccines and other purpose & $1(3.8)$ & $1(2.5)$ \\
\hline Non- electric fridge & $13(50.0)$ & $6(15.0)$ \\
\hline Non-refrigerated storage space & $5(19.2)$ & $23(57.5)$ \\
\hline Total & $26(100)$ & $40(100)$ \\
\hline \multicolumn{3}{|l|}{ Condition of fridge or freezer } \\
\hline Functional & $19(73.1)$ & $15(37.5)$ \\
\hline Non- functional & $7(26.9)$ & $25(62.5)$ \\
\hline Total & $26(100)$ & $40(100)$ \\
\hline
\end{tabular}

Source: Survey Data

Table 17: Major welfare challenges facing FLHWs

\begin{tabular}{|c|c|c|c|c|c|c|c|c|c|}
\hline \multirow[b]{2}{*}{ MNCH services provided } & \multicolumn{4}{|c|}{ Bauchi } & \multicolumn{4}{|c|}{ Cross River } & \multirow[b]{2}{*}{$\begin{array}{c}\text { Overal } \\
\text { Total } \\
\mathrm{N}=114\end{array}$} \\
\hline & $\begin{array}{l}\text { JCHEW } \\
\mathrm{N}=24\end{array}$ & $\begin{array}{l}\text { CHEW } \\
N=22\end{array}$ & $\begin{array}{l}\mathrm{CHO} \\
\mathrm{N}=1\end{array}$ & $\begin{array}{l}\text { Others } \\
\qquad \mathrm{N}=2\end{array}$ & $\begin{array}{l}\text { JCHEW } \\
\mathrm{N}=28\end{array}$ & $\begin{array}{l}\text { CHEW } \\
N=30\end{array}$ & $\begin{array}{l}\mathrm{CHO} \\
\mathrm{N}=6\end{array}$ & $\begin{array}{l}\text { Others } \\
\qquad \mathrm{N}=1\end{array}$ & \\
\hline $\begin{array}{l}\text { Low salary or remuneration for } \\
\text { FLHW }\end{array}$ & $17(70.8)$ & $12(54.5)$ & $0(0.0)$ & $1(50.0)$ & $23(82.1)$ & $21(70.0)$ & $5(83.3)$ & $0(0.0)$ & $78(68.4)$ \\
\hline Delays in payment of salaries & $19(79.2)$ & $12(54.5)$ & $1(100)$ & $0(0.0)$ & $17(60.7)$ & $22(73.3)$ & $5(83.3)$ & $1(100)$ & $77(67.5)$ \\
\hline $\begin{array}{l}\text { Distance between where FLHW } \\
\text { reside and where staff work }\end{array}$ & $15(62.5)$ & $8(36.4)$ & $0(100)$ & $1(50.0)$ & $14(50.0)$ & $16(53.3)$ & $4(66.7)$ & $1(100)$ & $59(51.8)$ \\
\hline $\begin{array}{l}\text { No residence rooms at the } \\
\text { health posts }\end{array}$ & $12(50.0)$ & $6(27.3)$ & $1(100)$ & $0(0.0)$ & $18(64.3)$ & $17(56.7)$ & $1(16.7)$ & $1(100)$ & $56(49.1)$ \\
\hline
\end{tabular}



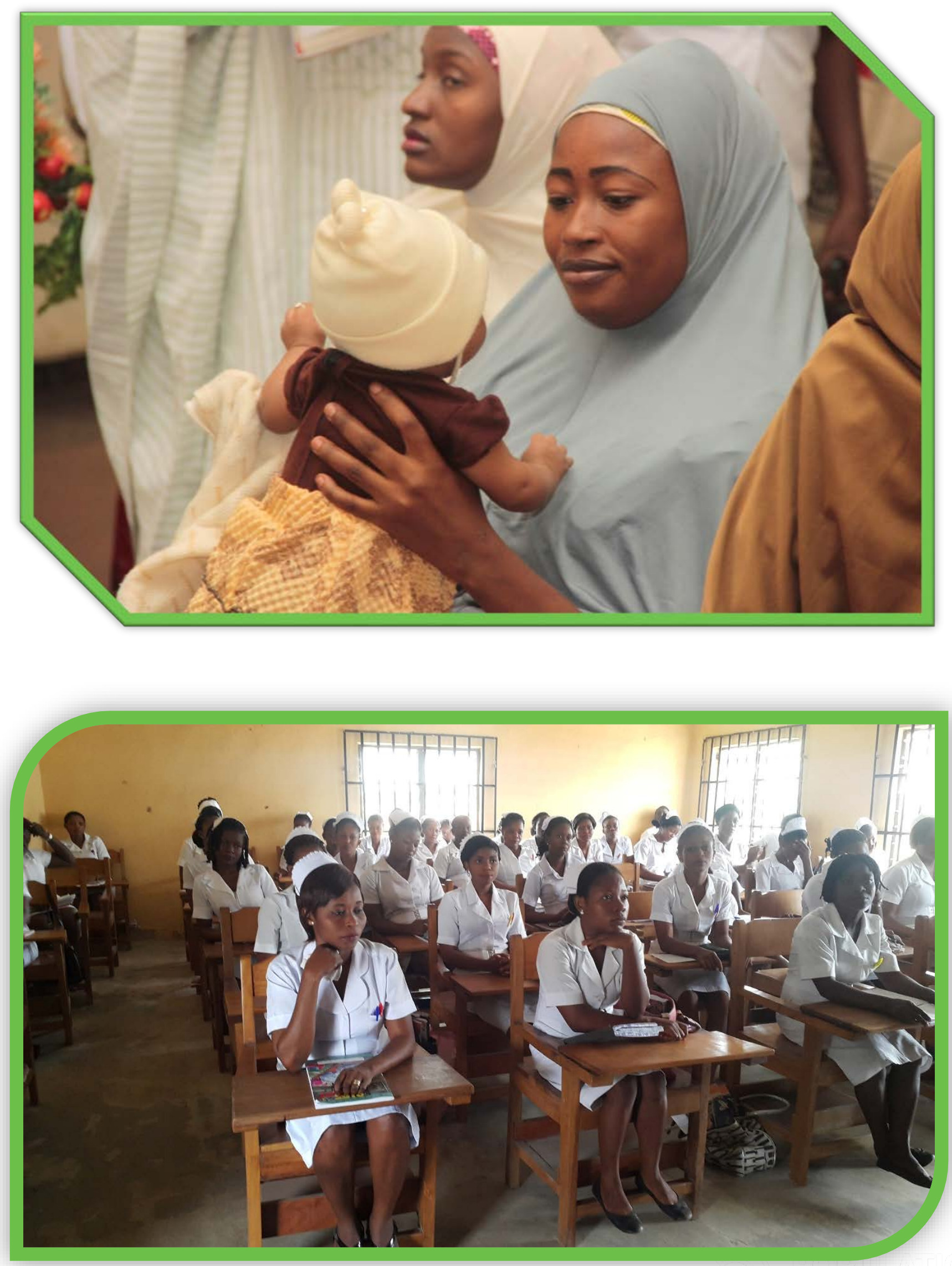

\section{POPULATION COUNCIL}

